\title{
Solid, Solution and Gas Phase Interactions of an Imidazolium-Based Task-Specific Ionic Liquid Derived from Natural Kojic Acid
}

\author{
Brenno A. D. Neto, ${ }^{* a}$ Alberto A. R. Mota, ${ }^{a}$ Claudia C. Gatto, ${ }^{a}$ Giovanna Machado, ${ }^{b}$ Maíra Fasciotti, ${ }^{c, d}$ \\ Heibbe C. B. de Oliveira, ${ }^{a}$ Davi A. C. Ferreira, ${ }^{a}$ Otavio Bianchi ${ }^{e}$ and Marcos N. Eberlin ${ }^{c}$
}

${ }^{a}$ Laboratory of Medicinal and Technological Chemistry, Chemistry Institute, University of Brasília (UnB), Campus Universitário Darcy Ribeiro, P.O. Box 4478, 70904-970 Brasília-DF, Brazil

${ }^{b}$ Center for Strategic Technologies of the North East (CETENE), Av. Prof. Luiz Freire, 1, 50740-540 Recife-PE, Brazil

${ }^{c}$ ThoMSon Mass Spectrometry Laboratory, University of Campinas (Unicamp), P.O. Box 6154, 13083-970 Campinas-SP, Brazil

${ }^{d}$ Institute of Metrology (Inmetro), Av. Nossa Senhora das Graças, 50, 25250-020 Duque de Caxias-RJ, Brazil

ePrograma de Pós-Graduação em Ciência e Engenharia de Materiais (PGMAT), Universidade de Caxias do Sul (UCS), Rua Francisco Getúlio Vargas, 1130, 95070-560 Caxias do Sul-RS, Brazil

\begin{abstract}
Um líquido iônico imidazólio de função específica derivado do ácido kójico natural teve suas interações supramoleculares investigadas no estado sólido, em solução e em fase gasosa. Diferentes técnicas como difração de raios $\mathrm{X}$ de monocristal, espectroscopia de ressonância magnética nuclear (NMR), espectrofotometria UV-Vis, medidas de condutividade, espalhamento de raios X em baixo ângulo (SAXS), espectrometria de massas (tandem) com ionização por electrospray (ESI-MS(/MS)) e cálculos teóricos permitiram uma investigação estrutural aprofundada desse líquido iônico de função específica e suas interações supramoleculares.
\end{abstract}

An imidazolium-based task-specific ionic liquid derived from the natural kojic acid had its supramolecular interactions investigated in solid, solution and gas phase. The use of a set of techniques formed by single-crystal X-ray diffraction, nuclear magnetic resonance (NMR) spectroscopy, UV-Vis spectrophotometry, conductivity measurements, small angle X-ray scattering (SAXS), electrospray (tandem) mass spectrometry (ESI-MS(/MS)), and theoretical calculations allowed a deep investigation of the structural organization of the task-specific ionic liquid and its supramolecular interactions.

Keywords: ionic liquids, imidazolium, task-specific ionic liquids, supramolecular interactions, organization, X-ray, SAXS, UV-Vis, NMR, ESI-MS

\section{Introduction}

Ionic liquids (ILs) and task-specific ionic liquids (TSILs), especially those based on the imidazolium cation, are part of a class of attractive compounds of widespread use in many scientific and technological areas. ${ }^{1-3}$ These organic salts have already been successfully used in the chemical industry for many years. ${ }^{4}$ Their prominence is exemplified by many review articles recently published regarding several features of these unique chemical species. ${ }^{5-21}$

*e-mail: brenno.ipi@gmail.com
The possibility of tuning the physical and chemical properties of ILs and TSILs associated with their attractive physicochemical properties, such as very low vapor pressure, large electrochemical window, good thermal and chemical stabilities, have also opened a wealth of other applications for these ionic materials. Despite all progress already reached by ILs, fine details about their supramolecular organization, the importance of $\mathrm{H}$-bonds and a deep understanding on the directionality of imidazolium-based derivatives are only now emerging. Each IL/TSIL has unique physicochemical properties and it has been estimated that ca. $10^{6}$ combinations of known 
cations and anions may afford a new type of such ionic compounds. ${ }^{22}$ The effort towards a better comprehension on the physicochemical properties of such materials is therefore very challenging; and each new structure demands specific efforts and a set of characterizations to depict its unique structural features and properties. Despite the diversity, some general trends have been established, and it is, for instance, known that the physicochemical properties of ILs/TSILs are intimately associated with their ionic structures, ${ }^{23}$ that is, with the net result from a combination of entropic (H-bonds and dispersive forces) and enthalpic (Coulombic) contributions. ${ }^{2}$

Besides ionic interactions, whether supramolecular interactions also govern the organization of imidazoliumbased ILs is still hotly debated with a vast number of important contributions. ${ }^{24-29}$ Despite their importance, the number of significant contributions specifically discussing the supramolecular organization and interactions of TSILs is much scarcer ${ }^{30-45}$ when compared to nonfunctionalized ILs. TSILs have become one of the most important strategies for furthering IL chemistry, ${ }^{1}$ as noted for the large and increasing number of innovative applications described for these ionic compounds. ${ }^{46-48}$ TSILs, for instance, have been successfully used to form micelles with lower concentrations when compared with the nonfunctionalized micellar agent. ${ }^{30}$ Nanoparticle stabilizing agents, ${ }^{49}$ oxidative desulfurization compounds, ${ }^{50}$ organocatalysts for multicomponent reactions, ${ }^{51-54}$ reagents in Pd-catalyzed $\mathrm{C}-\mathrm{C}$ bond formation, ${ }^{55}$ asymmetric synthesi ${ }^{56}$ and others $^{57-59}$ are also examples of the potential of TSILs. We have also explored the chemistry of TSILs applying some derivatives as catalysts for multicomponent reactions, ${ }^{60-62}$ as ligands for organometallic investigations, ${ }^{63}$ as reagents for organic reactions mechanistic evaluations, ${ }^{64-66}$ as ligands for the formation of water-soluble lanthanide-based fluorescent probes ${ }^{67}$ and others. ${ }^{68-70}$

Motivated by their importance, and due to limited knowledge of the organizational, supramolecular interactions and physicochemical properties of TSILs, we have recently studied the structural organization and supramolecular interactions of the TSIL 1-methyl-3carboxymethylimidazolium chloride. ${ }^{71}$ Herein we wish to expand the knowledge of TSIL chemistry by disclosing a novel study on the supramolecular interactions and aggregate formation/stabilization of an imidazolium-based TSIL (Figure 1) derived from the natural kojic acid.

3-((5-Hydroxy-4-oxo-4H-pyran-2-yl)methyl)-1methyl-imidazolium chloride (MIK.Cl) is a known TSIL which we have described and used in some important catalytic transformations, such as oxidation, reduction and $\mathrm{C}-\mathrm{C}$ bond formation. ${ }^{68-70}$ Due to our interest in

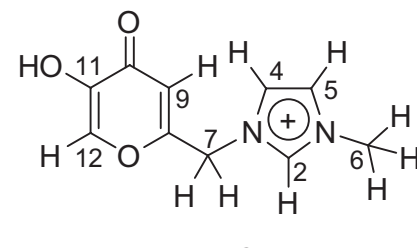

MIK.Cl<smiles>O=c1cc(CO)occ1O</smiles>

Kojic acid
Figure 1. (Left) Structure of the task-specific TSIL 3-((5-hydroxy-4-oxo4H-pyran-2-yl)methyl)-1-methyl-imidazolium chloride (MIK.Cl). The chloride anion has been omitted. (Right) Structure of the natural kojic acid.

the chemistry of MIK.Cl, we decided to perform a comprehensive evaluation of its properties in solid, solution and gas phase interactions by using a set of techniques formed by single-crystal X-ray diffraction, nuclear magnetic resonance (NMR) spectroscopy, UV-Vis spectrophotometry, conductivity measurements, small angle X-ray scattering (SAXS), electrospray (tandem) mass spectrometry (ESI-MS(/MS)), and theoretical calculations. The structural organization and supramolecular interactions found for MIK.Cl nicely highlight the importance of $\mathrm{H}$-bonds for the unique directionality of this important ionic compound, and details will be disclosed herein.

\section{Experimental}

See Supplementary Information for detailed experimental procedures, spectral data and analyses. CCDC (Cambridge Crystallographic Data Centre) 1015994 (MIK.Cl) contains the supplementary crystallographic data for this paper and the cif file can be obtained from the corresponding author.

\section{Results and Discussion}

\section{X-ray analysis}

The molecular structure of MIK.Cl has been initially investigated by single-crystal X-ray diffraction crystallographic analysis. Crystal and structure refinement data are summarized in Table 1. Molecules packing in stacks of MIK cations and $\mathrm{Cl}^{-}$anions, affording an extended network of cations and anions and showing the ionic channels, are visualized in Figure 2. Imidazolium cations are found organized through $\pi$-stacking interactions separated by $4.568(2) \AA$ of distance. The observed imidazolium stacking is similar to nonfunctionalized $\mathrm{ILs}^{72,73}$ and to other TSILs ${ }^{40}$ but with larger distance between the imidazolium rings. The 4-pyrone ring is also significantly organized through $\pi$-stacking interactions.

From the single-crystal X-ray analysis one cation is also depicted as being surrounded by three anions and, in 
Table 1. X-ray diffraction data collection and refinement parameters for MIK.Cl

\begin{tabular}{|c|c|}
\hline Chemical formula & $\mathrm{C}_{10} \mathrm{H}_{11} \mathrm{ClN}_{2} \mathrm{O}_{3}$ \\
\hline $\mathrm{M} /\left(\mathrm{g} \mathrm{mol}^{-1}\right)$ & 242.66 \\
\hline Crystal system & Monoclinic \\
\hline Space group & $P 2_{l} / c$ \\
\hline Unit cell $a$ / & $4.568(1)$ \\
\hline$b / \AA$ & $20.916(5)$ \\
\hline$c / \AA$ & $11.312(3)$ \\
\hline$V / \AA^{3}$ & 1079.15(5) \\
\hline $\mathrm{Z}$ & 4 \\
\hline $\mathrm{D}_{\mathrm{c}} /\left(\mathrm{g} \mathrm{cm}^{-3}\right)$ & 1.494 \\
\hline Index ranges & $-6 \leq h \leq 6$ \\
\hline \multicolumn{2}{|l|}{$-29 \leq \mathrm{k} \leq 29$} \\
\hline \multicolumn{2}{|l|}{$-16 \leq 1 \leq 16$} \\
\hline Absorption coefficient $/ \mathrm{mm}^{-1}$ & 0.347 \\
\hline Absorption correction & Multi-scan \\
\hline Max/min transmission & $0.9897 / 0.9498$ \\
\hline Measured reflections & 14141 \\
\hline Independent reflections / $\mathrm{R}_{\mathrm{int}}$ & $3333 / 0.0173$ \\
\hline Refined parameters & 151 \\
\hline $\mathrm{R} 1(\mathrm{~F}) / \mathrm{wR} 2\left(\mathrm{~F}^{2}\right)(\mathrm{I}>2 \sigma(\mathrm{I}))$ & $0.0369 / 0.01018$ \\
\hline GooF & 1.049 \\
\hline Largest diff. peak and hole / $\left(\mathrm{e} \AA^{-3}\right)$ & 0.352 and -0.279 \\
\hline CCDC deposit number & 1015994 \\
\hline
\end{tabular}

turn, chlorides are surrounded by three cations (Figure 3 ). Table 2 summarizes the close contact distances and angles shown in Figure 3.

H-bonds may be classified using the cutoff limits of $3.2 \AA$ for distances and above $110^{\circ}$ for angles (conservative option) as following the criteria of Steiner. ${ }^{74}$ Using these limits, all entries (1-7) in Table 2 may still be classified as $\mathrm{H}$-bonds. No cation-anion interaction is noted at the C5 position in the imidazolium ring. A strong interaction with the oxygen $(\mathrm{C}=\mathrm{O})$ of a second cation is indeed the major interaction for $\mathrm{C} 2-\mathrm{H} 2$ and $\mathrm{C} 7-\mathrm{H} 7 \mathrm{~A}$ (Figure 3, right). The strongest $\mathrm{H}$-bond is noted for the chloride interaction with

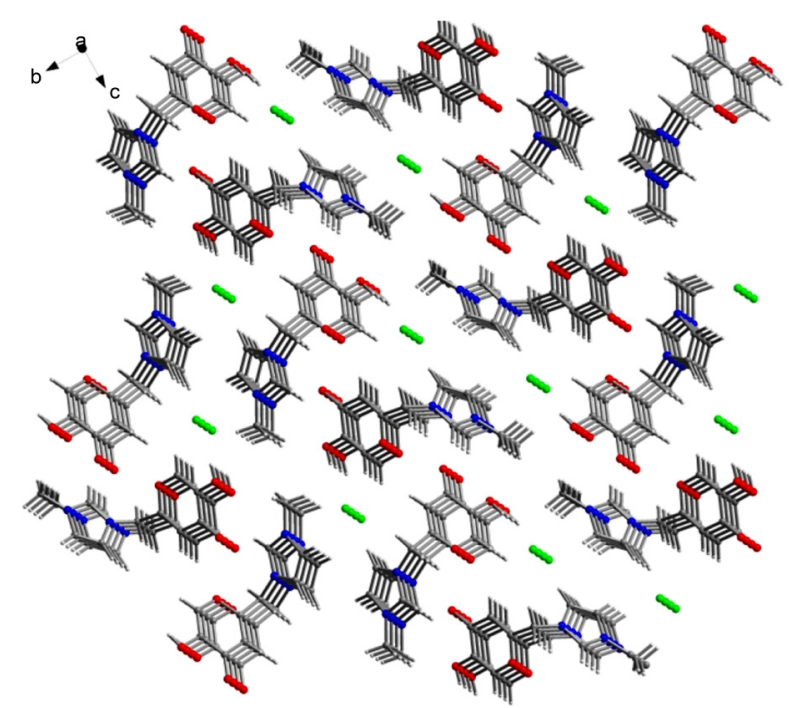

Figure 2. View of the crystal structure of MIK.Cl showing ionic channel formation in the packed molecules.

the most acidic hydrogen (O15-H15) bearing a 2.236(4) $\AA$ of distance and an angle of ca. $174^{\circ}$ (O15-H15 ‥Cl16). The anion also displayed interactions with $\mathrm{C} 12-\mathrm{H} 12$ and C4-H4 but no interaction at all is noted at $\mathrm{C} 5-\mathrm{H} 5$ position, in contrast with nonfunctionalized ILs.

\section{NMR analysis}

NMR is a powerful technique for IL studies. ${ }^{75}$ D NMR techniques are much explored for revealing different features of IL structural organization in solution and aiming at a better comprehension of the supramolecular interactions. ${ }^{76-78}$ Proton spin-lattice relaxation times (T1) is ${ }^{79}$ however, a well-known NMR technique which can be efficiently applied for the cation-anion interactions and supramolecular aggregate formation studies. T1 measurements will be directly influenced by molecular dynamics and chemical environment changes, as already established. T1 is therefore a NMR technique that can

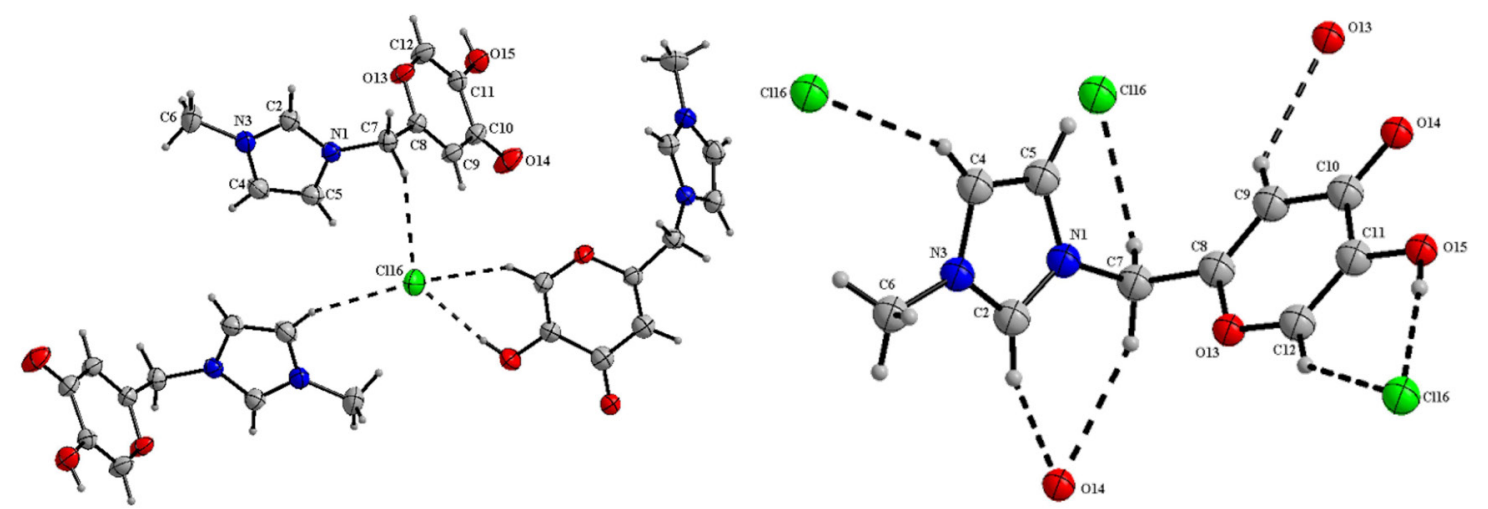

Figure 3. Highlighted interactions observed for MIK.Cl. (Left) View of the close contacts for the $\mathrm{Cl}^{-}$anion. (Right) Local structure and close contacts around a single cation (MIK). Note that one anion is surrounded by three cations and that each cation is surrounded by three anions. 
Table 2. Distance of close contacts and angles for the anion and for the cation of MIK.Cl

\begin{tabular}{|c|c|c|c|c|}
\hline entry & Atom 1 & Atom 2 & Distance / 凡 & Angle / degree \\
\hline 1 & $\mathrm{C} 116$ & $\mathrm{H} 7 \mathrm{~A}$ & $2.724(4)$ & 152.19(6) (C7-H7A …C116) \\
\hline 2 & $\mathrm{Cl16}$ & $\mathrm{H} 4$ & $2.707(2)$ & $154.90(2)(\mathrm{C} 4-\mathrm{H} 4 \cdots \mathrm{Cl} 16)$ \\
\hline 3 & C116 & H15 & $2.236(4)$ & 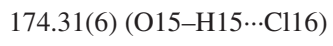 \\
\hline 4 & $\mathrm{Cl16}$ & H12 & $2.657(4)$ & $140.03(7)(\mathrm{C} 12-\mathrm{H} 12 \cdots \mathrm{Cl1})$ \\
\hline 5 & $\mathrm{O} 13$ & H9 & $2.544(8)$ & $141.96(7)(\mathrm{C} 9-\mathrm{H} 9 \cdots \mathrm{O} 13)$ \\
\hline 6 & $\mathrm{O} 14$ & $\mathrm{H} 2$ & $2.140(2)$ & $146.64(8)(\mathrm{C} 2-\mathrm{H} 2 \cdots \mathrm{O} 14)$ \\
\hline 7 & $\mathrm{O} 14$ & H7B & $2.492(1)$ & $144.50(6)(\mathrm{C} 7-\mathrm{H} 7 \mathrm{~B} \cdots \mathrm{O} 14)$ \\
\hline
\end{tabular}

be applied for critical aggregation concentration (CAC) determination, as shown for some ammonium surfactants. ${ }^{80}$ Despite the useful information provided by $\mathrm{T} 1$, this technique has only been recently applied for depicting the supramolecular interactions of TSILs. ${ }^{71}$

We have therefore performed $\mathrm{T} 1$ measurements to study MIK.Cl interactions. A sealed capillary tube filled with benzene- $d_{6}$ (external reference to set the scale at $7.16 \mathrm{ppm}$ for ${ }^{1} \mathrm{H}$ and $128.4 \mathrm{ppm}$ for ${ }^{13} \mathrm{C}$ ) was used. Supplementary Information Figure $\mathrm{S} 1$ shows both ${ }^{1} \mathrm{H}$ and ${ }^{13} \mathrm{C}$ NMR of MIK.Cl. T1 measurements were performed in $\mathrm{D}_{2} \mathrm{O}$, $\mathrm{D}_{2} \mathrm{O}: \mathrm{CD}_{3} \mathrm{OD}(1: 1 \mathrm{v} / \mathrm{v})$ and $\mathrm{D}_{2} \mathrm{O}: \mathrm{CD}_{3} \mathrm{CN}(1: 1 \mathrm{v} / \mathrm{v})$ to probe both the intermolecular interactions and the importance of the H-bonds for the supramolecular aggregate formation. Table 3 summarizes the T1 measurement results under optimized conditions. Figures 4, 5 and 6 show the obtained results for the experiments.

$\mathrm{T} 1$ experiments provided very elucidative data. In pure $\mathrm{D}_{2} \mathrm{O}$, a transition phase for the CAC, that is, for larger supramolecular aggregate formation, is noted for concentrations a little higher than $0.6 \mathrm{~mol} \mathrm{~L}^{-1}$. For concentrations above this transition, dipole-dipole relaxations are likely favored and therefore the observed $\mathrm{T} 1$ have a tendency to be lower. $\mathrm{C}(12)-\mathrm{H}$ proved to be the most sensitive to the environmental changes in the structure of MIK.Cl. When the experiments were conducted in a solvent mixture of $\mathrm{D}_{2} \mathrm{O}: \mathrm{CD}_{3} \mathrm{OD}$, an almost complete disruption of the aggregation is noted. A small transition could be noted for C(9)-H (Figure 5). C(12)-H and C(9)-H are both attached to the chromophore moiety (4-pyrone ring). The experiments in $\mathrm{D}_{2} \mathrm{O}: \mathrm{CD}_{3} \mathrm{CN}$ showed lower $\mathrm{CAC}$ values and close to $0.2 \mathrm{~mol} \mathrm{~L}^{-1}$. The hydrogens in the pyrone ring were again the most affected by the increase in the TSIL concentration. Phase transition was only noted for $\mathrm{C}(4)-\mathrm{H}$, which is the closest hydrogen in the imidazolium ring to the pyrone ring. Overall, the $\mathrm{T} 1$ results indicate, therefore, somehow surprisingly, that aggregate formation can be easily broken and point to an aggregation directed by the 4-pyrone ring instead of the imidazolium ring. In the UVVis section this feature will be once more evaluated.

The solvent effect experiments also pointed to solventseparated ion pairs when methanol (or acetonitrile) is added in the aqueous solution with MIK.Cl, in accordance with similar observations for nonfunctionalized imidazolium

Table 3. Relaxation times (s) for MIK.Cl ( $\left.0.318 \mathrm{~mol} \mathrm{~L}^{-1}\right)$ diluted with different solvents at optimized conditions

\begin{tabular}{|c|c|c|c|}
\hline Hydrogen & $\mathrm{T} 1$ (error) in pure $\mathrm{D}_{2} \mathrm{O}$ & $\mathrm{T} 1$ (error) in $\mathrm{D}_{2} \mathrm{O}: \mathrm{CD}_{3} \mathrm{OD}(1: 1 \mathrm{v} / \mathrm{v})$ & $\mathrm{T} 1$ (error) in $\mathrm{D}_{2} \mathrm{O}: \mathrm{CD}_{3} \mathrm{CN}(1: 1 \mathrm{v} / \mathrm{v})$ \\
\hline $\mathrm{C}(2)-\mathrm{H}$ & $2.588( \pm 0.148)$ & $1.935( \pm 0.158)$ & $3.366( \pm 0.192)$ \\
\hline $\mathrm{C}(4)-\mathrm{H}$ & $3.319( \pm 0.187)$ & $3.393( \pm 0.201)$ & $5.273( \pm 0.325)$ \\
\hline $\mathrm{C}(5)-\mathrm{H}$ & $4.585( \pm 0.288)$ & $2.585( \pm 0.188)$ & $4.173( \pm 0.290)$ \\
\hline $\mathrm{C}(6)-\mathrm{H}_{3}$ & $2.045( \pm 0.124)$ & $1.747( \pm 0.150)$ & $2.344( \pm 0.156)$ \\
\hline $\mathrm{C}(7)-\mathrm{H}_{2}$ & $0.937( \pm 0.075)$ & $0.698( \pm 0.085)$ & $1.088( \pm 0.087)$ \\
\hline $\mathrm{C}(9)-\mathrm{H}$ & $3.176( \pm 0.166)$ & $2.899( \pm 0.193)$ & $4.191( \pm 0.295)$ \\
\hline $\mathrm{C}(12)-\mathrm{H}$ & $3.821( \pm 0.203)$ & $5.501( \pm 0.294)$ & $6.585( \pm 0.366)$ \\
\hline
\end{tabular}



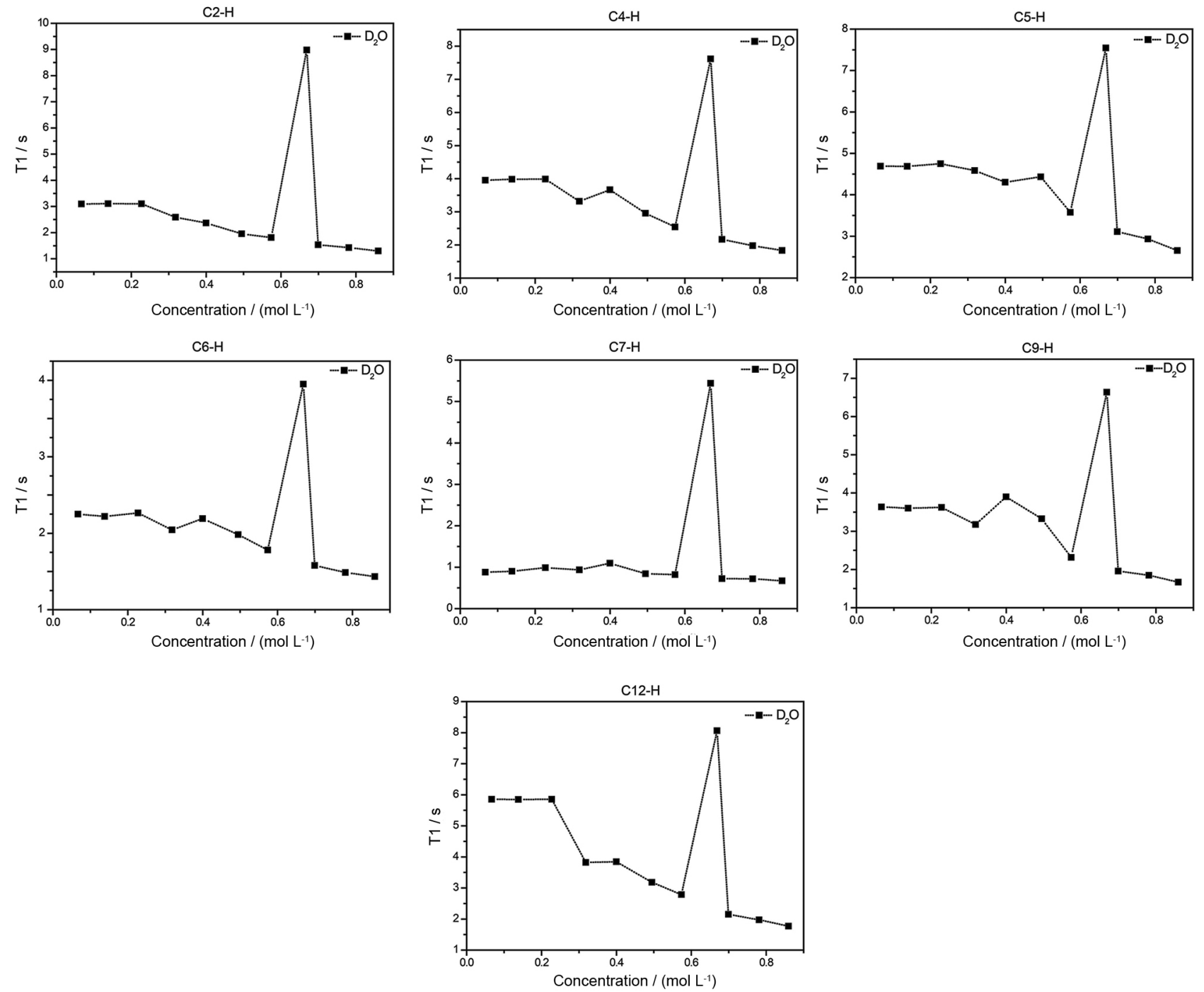

Figure 4. $\mathrm{T} 1$ values for the hydrogens of $\mathrm{MIK}$.Cl under different concentrations in pure $\mathrm{D}_{2} \mathrm{O}$. Each point refers to an independent experiment.

ILs $^{81}$ and for TSILs, ${ }^{71}$ therefore breaking any large supramolecular aggregate.

Chemical shifts for the imidazolium hydrogens and the other hydrogens failed to display significant changes upon increasing the TSIL concentration in the ${ }^{1} \mathrm{H}$ NMR spectra (Figure S2). This behavior is again coherent with the observation that aggregate formation is driven through the pyrone ring instead of the imidazolium cation. When the aggregation is driven by the imidazolium moiety, chemical shift dependence of the imidazolium hydrogens and of the other hydrogens have been typically noted for ILs $^{73}$ and TSILs. ${ }^{71}$

\section{Conductivity analysis}

Considering conductivity measurements are straightly associated with free ions in solution, this technique has been used as a powerful tool for the investigation of ILs/
TSILs in solution, ${ }^{82}$ especially for aqueous solutions of such ionic materials. ${ }^{83}$

Following Kohlrausch's empirical law $\left(\Lambda m=\Lambda_{0}-\mathrm{kC}^{-1 / 2}\right.$, where $\mathrm{C}$ is the concentration), conductivity analysis were therefore performed and analyzed (Figure 7) for different solvents and mixtures $\left(\mathrm{H}_{2} \mathrm{O}, \mathrm{MeOH}, \mathrm{MeCN}, \mathrm{H}_{2} \mathrm{O}: \mathrm{MeOH}\right.$, and $\mathrm{H}_{2} \mathrm{O}: \mathrm{MeCN}$ mixtures). Two distinct breaks in the Kohlrausch plots are noted for most solvent mixtures. These breaks indicate two regimes of differing aggregate nature, as previously shown for nonfunctionalized ILs. ${ }^{83}$ Table 4 reports the concentrations at which the break points ( $\alpha$ and $\beta$ regimes) occur.

Data in Table 4 show that upon increasing the organic solvent concentration the second regime of aggregation $(\beta)$ is not noted anymore. This effect is more pronounced for methanolic solutions rather than for acetonitrile-containing solutions. The competitive H-bonds with methanol force the aggregates to break. On the whole, the results are also 

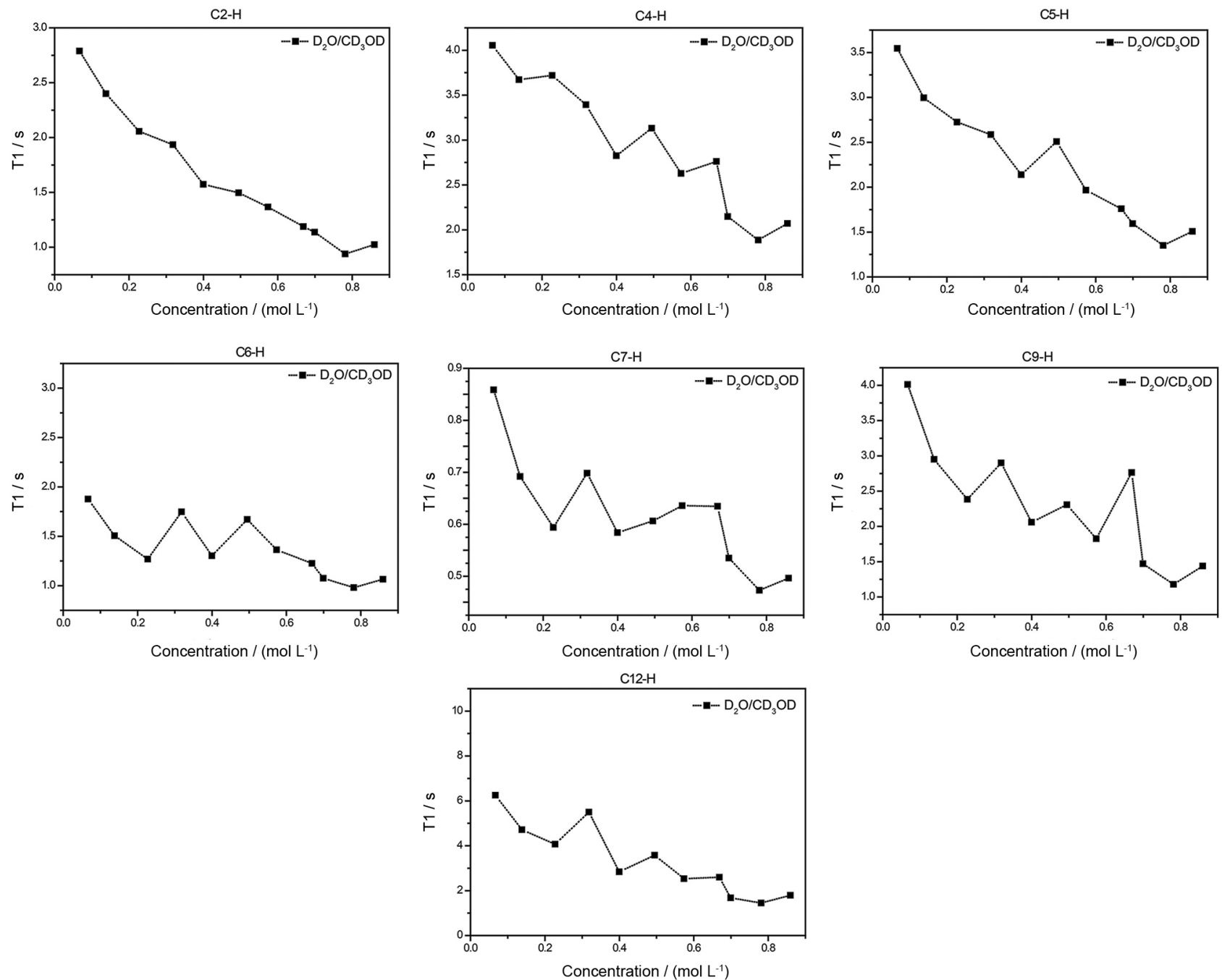

Figure 5. $\mathrm{T} 1$ values for the hydrogens of $\mathrm{MIK} . \mathrm{Cl}$ under different concentrations in $\mathrm{D}_{2} \mathrm{O}: \mathrm{CD}_{3} \mathrm{OD}(1: 1 \mathrm{v} / \mathrm{v})$. Each point refers to an independent experiment.

in accordance with the fact that aggregation easily takes place in water rather than in other solvents.

\section{UV-Vis analysis}

Microenvironment changes in $\pi$-conjugated systems such as imidazolium derivatives may be monitored by UV-Vis analyses. Imidazolium-based ${ }^{84}$ (and other substances ${ }^{85}$ ) had already their aggregation behavior and nanostructures (from self-assembling) depicted by UV-Vis analyses.

$\mathrm{UV}-\mathrm{Vis}$ analyses were therefore conducted in $\mathrm{H}_{2} \mathrm{O}$, $\mathrm{MeOH}, \mathrm{MeCN}, \mathrm{H}_{2} \mathrm{O}: \mathrm{MeOH}$, and $\mathrm{H}_{2} \mathrm{O}: \mathrm{MeCN}$ mixtures (Figures S3-S6). The second derivative from the UV-Vis spectra was applied to precisely determine $1_{\max }$ of absorption and the shifts caused by solvent effects (ca. $225 \mathrm{~nm}$ for the imidazolium ring and ca. $274 \mathrm{~nm}$ for the pyrone ring). Determination of such values (Figure 8) allows a relationship between solvent effects on the $1_{\max }$ of absorption and the shifts of wavelength through an aggregation regime to be made.
No significant changes could be noted for the imidazolium ring indicating, therefore, that aggregation is taking place preferentially through the chromophore, that is, the pyrone ring. For concentrations above $0.15 \mathrm{mmol} \mathrm{L}^{-1}$, larger supramolecular aggregates may occur and shifts are noted for absorption and wavelength $\lambda_{\max }$ (Figure 8).

\section{SAXS analysis}

SAXS analysis was applied in this study aiming at understanding the local organization of cations and anions of MIK.Cl, especially because ILs/TSILs show complex local organization with self-aggregating polar and non-polar domains of nanometer size. ${ }^{2}$ This knowledge is important particularly because the resulting ion-ion associations will have an impact on the ionic transport properties. More detailed information about the interaction of ILs/TSILs with different solvents may be 

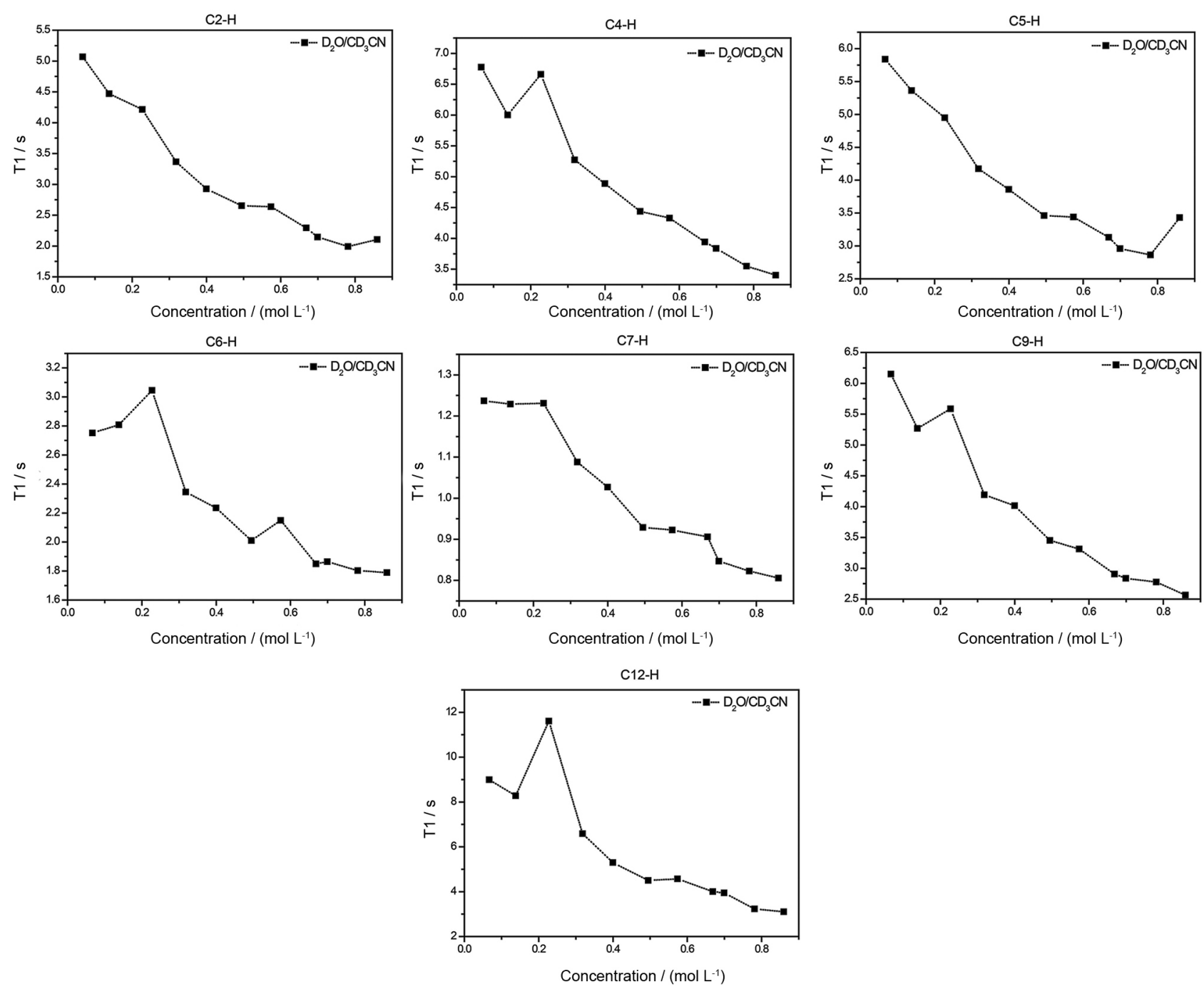

Figure 6. T1 values for the hydrogens of MIK.Cl under different concentrations in $\mathrm{D}_{2} \mathrm{O}: \mathrm{CD}_{3} \mathrm{CN}(1: 1 \mathrm{v} / \mathrm{v})$. Each point refers to an independent experiment.

therefore obtained from SAXS analyses. Figure 9 shows a detailed data analysis regarding saturated aqueous and methanolic solutions of MIK.Cl.

Using the two phase model, ${ }^{71,86-88}$ the length of the aggregates was obtained. The long period (L) was calculated by means of the first maximum correlation function, $\gamma(r)$, corresponding to an enhancement of the most probable distance between the two centers of gravity (MIK.Cl aggregates), as recently applied for other TSIL (see details in the Supplementary Information). ${ }^{71}$

Figure 9 indicates from the intensity values of the $\gamma(r)$ function that there is a presence of semi-ordered phases for MIK.Cl in water, which is a more organized solution when compared with methanolic solution. This observation, depicted by SAXS analyses, is in accordance with the previously described techniques.

The first maximum in the experimental G(r) function can be estimated as disordered solvent-phase, represented by Lm. The model considers MIK.Cl (semi-ordered phase) structure to be surrounded by solvent (semi-ordered phase). From the subtraction of $\mathrm{L}$ from $\gamma(\mathrm{r})$ and $\mathrm{Lm}$ (first maximum in $G(r)$ ), the value of the distance between the two scattering centers without solvent around the aggregates is obtained. The molecular lengths found were 0.70 and $2.6 \mathrm{~nm}$ for water and methanol solutions, respectively. Using the molecular diameter data for water, ${ }^{89} 0.25 \mathrm{~nm}$, and $0.42 \mathrm{~nm}$ for methanol,,${ }^{90}$ it is possible to determine the number of molecules neighboring MIK. $\mathrm{Cl}$. The calculations revealed the presence of up to three molecules surrounding MIK.Cl for the aqueous solution and six for the methanolic solution. IL/TSIL-solvent interactions are dependent on the ligand type and its acidic strength in solution (pKa). ${ }^{91}$ For TSILs with ligands with small $\mathrm{pKa}$ values, the interaction with methanol is therefore increased. ${ }^{71}$ Despite the acidic character of MIK. $\mathrm{Cl}$, it is not as acidic as other $-\mathrm{COOH}$-functionalized 

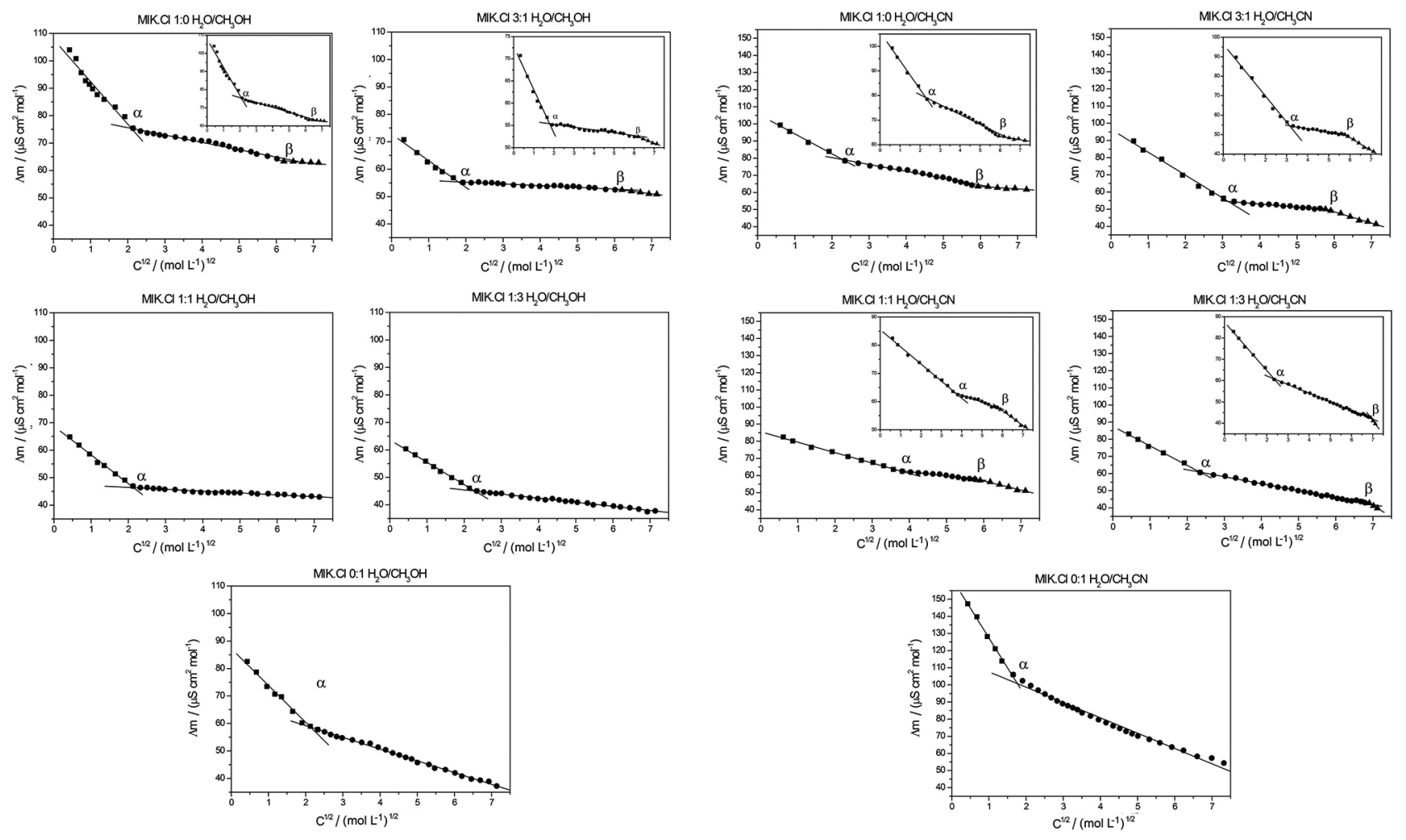

Figure 7. $\mathrm{C}^{-1 / 2} v s . \Lambda m$ of $\mathrm{MIK} . \mathrm{Cl}$ in different (left) $\mathrm{H}_{2} \mathrm{O} / \mathrm{MeOH}$ and (right) $\mathrm{H}_{2} \mathrm{O} / \mathrm{MeCN}$ mixtures at several concentrations.

Table 4. Solvent proportions and break points ( $\alpha$ and $\beta$ regimes) obtained from Kohlrausch's empirical law application

\begin{tabular}{lcc}
\hline \multirow{2}{*}{$\begin{array}{l}\text { Solvent and } \\
\text { proportion mixture }\end{array}$} & \multicolumn{2}{c}{ Concentration $/\left(\mathrm{mmol} \mathrm{L}^{-1}\right)$} \\
\cline { 2 - 3 } $\mathrm{H}_{2} \mathrm{O} / \mathrm{CH}_{3} \mathrm{OH} 0: 1$ & $4.59-5.49$ & $\beta$ \\
$\mathrm{H}_{2} \mathrm{O} / \mathrm{CH}_{3} \mathrm{OH} 3: 1$ & $3.68-4.59$ & $36.19-38.46$ \\
$\mathrm{H}_{2} \mathrm{O} / \mathrm{CH}_{3} \mathrm{OH} 1: 1$ & $4.52-5.40$ & - \\
$\mathrm{H}_{2} \mathrm{O} / \mathrm{CH}_{3} \mathrm{OH} 1: 3$ & $5.40-3.98$ & - \\
$\mathrm{H}_{2} \mathrm{O} / \mathrm{CH}_{3} \mathrm{OH} 0: 1$ & $5.40-6.38$ & - \\
$\mathrm{H}_{2} \mathrm{O} / \mathrm{CH}_{3} \mathrm{CN} 0: 1$ & $5.52-7.34$ & $33.24-35.22$ \\
$\mathrm{H}_{2} \mathrm{O} / \mathrm{CH}_{3} \mathrm{CN} 3: 1$ & $10.94-12.43$ & $31.58-33.25$ \\
$\mathrm{H}_{2} \mathrm{O} / \mathrm{CH}_{3} \mathrm{CN} 1: 1$ & $14.50-16.26$ & $33.25-34.89$ \\
$\mathrm{H}_{2} \mathrm{O} / \mathrm{CH}_{3} \mathrm{CN} 1: 3$ & $5.52-7.34$ & $46.09-47.65$ \\
$\mathrm{H}_{2} \mathrm{O} / \mathrm{CH}_{3} \mathrm{CN} \mathrm{0:1}$ & $2.73-3.63$ & - \\
\hline
\end{tabular}

TSILs, ${ }^{71}$ therefore this behavior results in larger disorder of the system and contributes to an increased amount of molecules in methanolic solutions.

\section{ESI-MS(/MS)}

MS has proved to be an unsurpassed tool for the investigation of IL/TSIL structures and physicochemical properties, as reviewed elsewhere. ${ }^{8}$ This fast, efficient and precise technique can be applied for online monitoring of ionic compositions through continuous snapshots of the species present in solution with a gentle transfer to the gas-phase. ESI-MS(/MS) has therefore acted as a bridge which connects solution and gas-phase chemistries; ${ }^{92}$ and has been therefore used herein to investigate MIK. $\mathrm{Cl}$ interactions. For that, $100 \mathrm{mmol} \mathrm{L}^{-1}$ solutions (water, methanol and water-methanol $1: 1 \mathrm{v} / \mathrm{v})$ were directly infused and monitored online. Figure 10 shows the ESI(+)-MS spectra, whereas Figure 11 shows the respective ESI(+)-MS/MS spectra for some key species.

As Figure 10 shows, MIK cation was detected as an abundant ion of $m / z 207$. Two MIK aggregates were also detected and further characterized by collision-induced dissociation (CID, Figure 11), that is, the MIK cation associated with its zwitterionic partner (aggregate of $m / z$ 213) and two MIK cations associated with one chlorine anion (aggregate of $\mathrm{m} / \mathrm{z} 449$ ), respectively. Fortunately, these unprecedented species that were likely fished out directly from solution, were also found to represent long-lived gaseous species and their structures could be investigated via CID (Figure 11), with a dissociation chemistry that is in accordance with the proposed supramolecular structures.

In the experiments using a $100 \mathrm{mmol} \mathrm{L}^{-1}$ solution of $\mathrm{H}_{2} \mathrm{O}: \mathrm{MeOH}(1: 1 \mathrm{v} / \mathrm{v})$, only the aggregate of $m / z, 413$ could 


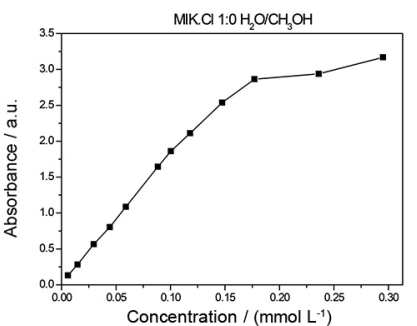

MIKCl $3: 1 \mathrm{H}_{2} \mathrm{O} / \mathrm{CH}_{3} \mathrm{OH}$

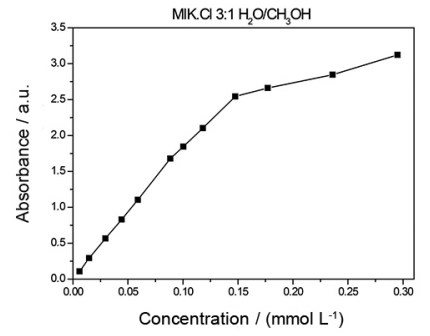

MK.C 1:1 $1 \mathrm{H}_{2} \mathrm{O} \mathrm{CH}_{3} \mathrm{OH}$

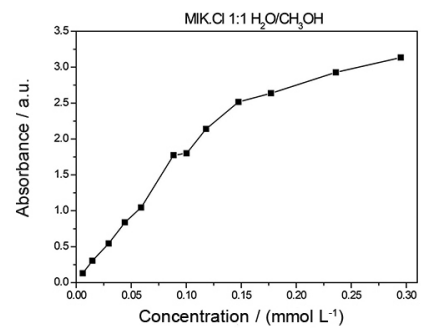

$\mathrm{MIKCO} 1: 3 \mathrm{H}_{2} \mathrm{O} / \mathrm{CH}_{3} \mathrm{OH}$

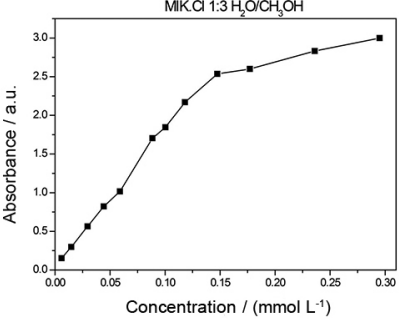

MK. $00: 1 \mathrm{H}_{2} \mathrm{O} / \mathrm{CH}_{3} \mathrm{OH}$

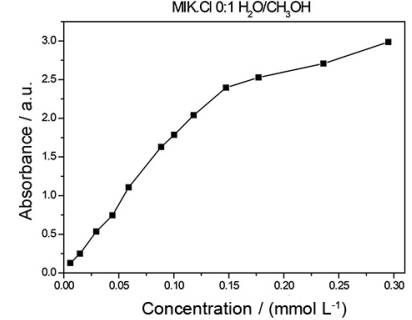

$\mathrm{MIKCl} 1: \mathrm{OH}_{2} \mathrm{O} / \mathrm{CH}_{3} \mathrm{OH}$

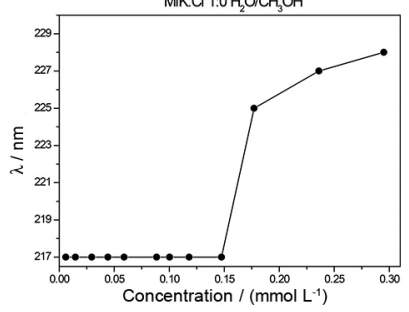

MIK.C $3: 1 \mathrm{H}_{2} \mathrm{O} / \mathrm{CH}_{3} \mathrm{OH}$

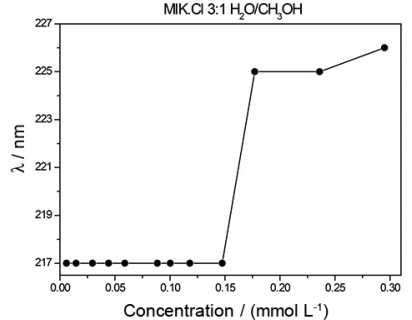

MIK.Cl 1:1 $\mathrm{H}_{2} \mathrm{O} / \mathrm{CH}_{3} \mathrm{OH}$

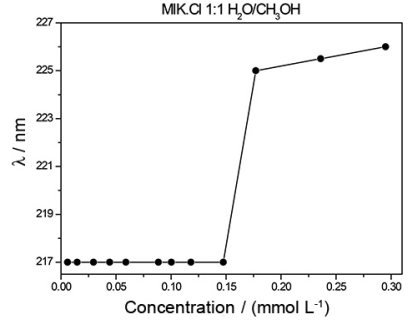

MIK.CI 1:3 $\mathrm{H}_{2} \mathrm{O} / \mathrm{CH}_{3} \mathrm{OH}$

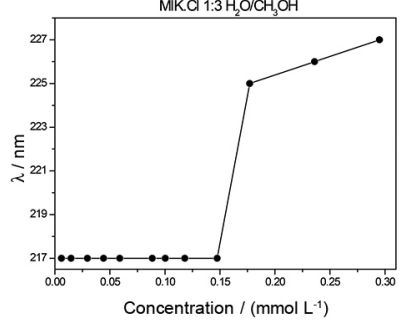

MK.Cl $0: 1 \mathrm{H}_{2} \mathrm{O}_{1} \mathrm{CH}_{3} \mathrm{OH}$

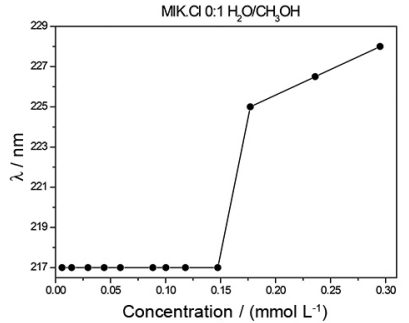

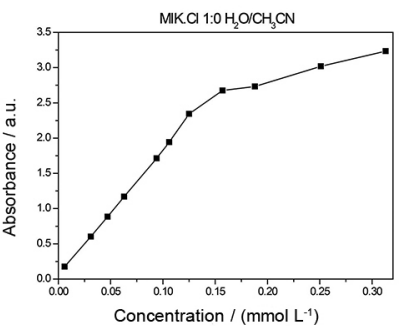

МाK. $3: 1 \mathrm{H}_{2} \mathrm{O} / \mathrm{CH}_{3} \mathrm{CN}$

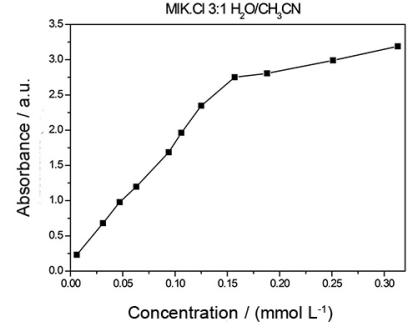

MIK Cl 1:1 $\mathrm{H}_{2} \mathrm{O} / \mathrm{CH}_{3} \mathrm{CN}$

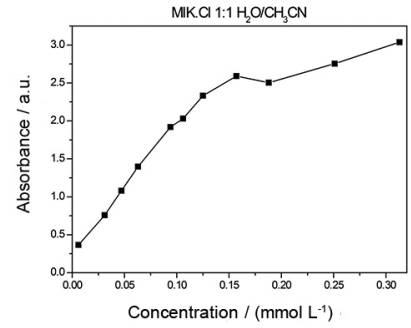

MK. $1: 3 \mathrm{H}_{2} \mathrm{O} / \mathrm{CH}_{3} \mathrm{CN}$

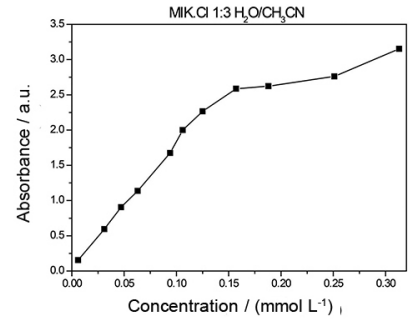

MK. $00: 1 \mathrm{H}_{2} \mathrm{O} / \mathrm{CH}_{3} \mathrm{CN}$

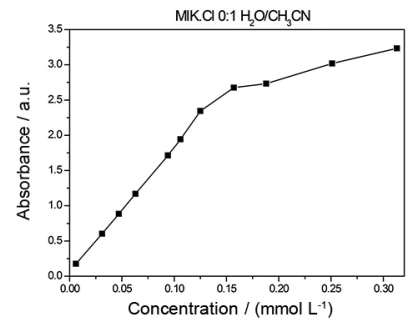

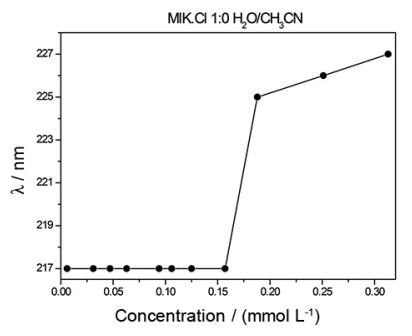

MIK. $\mathrm{Cl}: 1 \mathrm{H}_{2} \mathrm{O} / \mathrm{CH}_{3} \mathrm{CN}$

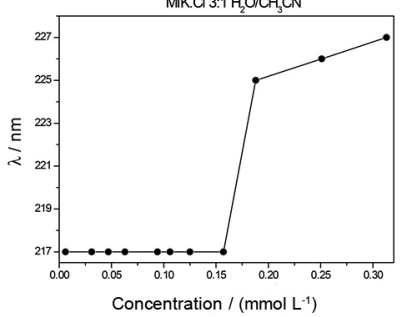

MIK. 1 1:1 $\mathrm{H}_{2} \mathrm{OCH}_{3} \mathrm{CN}$

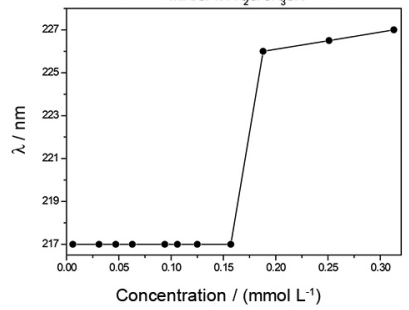

MK.C 1:3 $\mathrm{H}_{2} \mathrm{O} / \mathrm{CH}_{3} \mathrm{CN}$

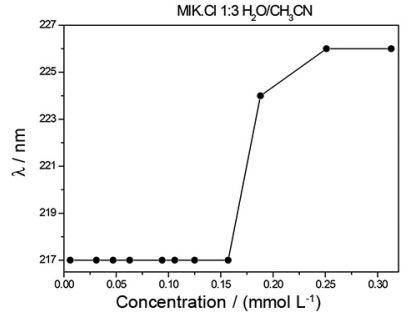

MIK CI 0:1 $\mathrm{H}_{2} \mathrm{OCH} \mathrm{CH}_{3} \mathrm{CN}$

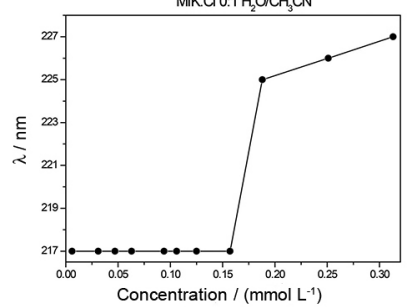

Figure 8. Absorbance $v s$. concentration and wavelength $v s$. concentration at different concentrations of MIK.Cl in water, methanol, acetonitrile, methanolwater and acetonitrile-water mixtures.

be observed, whereas the experiments with pure methanol (100 mmol L ${ }^{-1}$ solution) no aggregate could be observed (data not shown). These results are in accordance with the observations already described, indicating the preferential aggregation of MIK.Cl in aqueous solutions.

\section{Theoretical calculations}

Aiming at achieving a better understanding of the nature of the contributions for the aggregate formation of MIK.Cl, we have also performed theoretical calculations.
MP2/6-311+g* level of theory was selected since we have demonstrated this to be an appropriate level of calculations for TSILs ${ }^{71}$ (see more details in the Supplementary Information). Crystallographicallydetermined coordinates were taken frozen during all calculations, which were obtained at the MP2/6-311+G* level of theory.

Morokuma's recommendations were used for energy decomposition (deconvolution) analysis of the total energy (internal energy). The total energy $(\Delta \mathrm{E})$ was considered as the sum of the steric $\left(\Delta \mathrm{E}_{\text {steric }}\right.$, associated with 
electrostatic attraction and Pauling repulsion energies) and orbitalar contributions $\left(\Delta \mathrm{E}_{\text {orb }}\right)$, that is, $\Delta \mathrm{E}=\Delta \mathrm{E}_{\text {steric }}+\Delta \mathrm{E}_{\text {orb }}$.

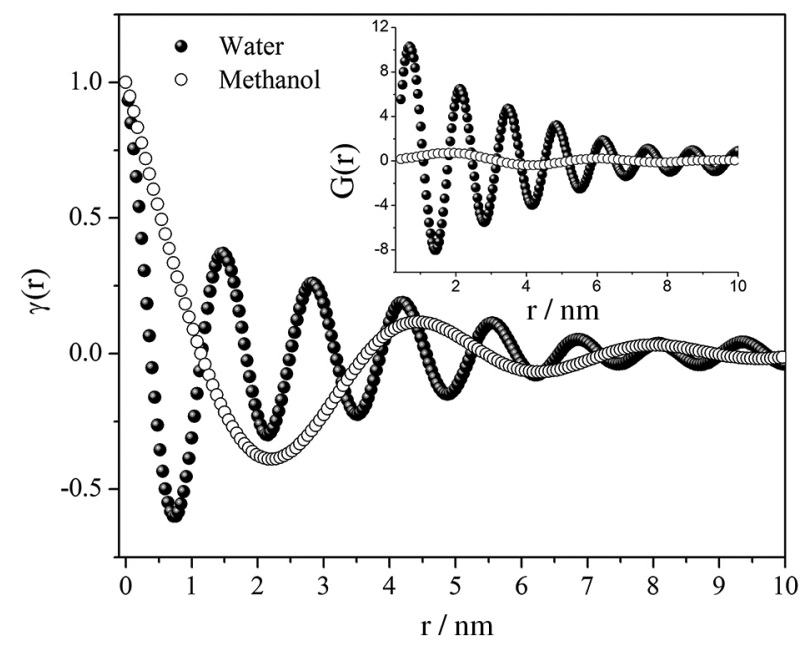

Figure 9. SAXS results for MIK.Cl in methanol and water (saturated solutions).
Figure 12 shows the relative energies of ion-pairing and the considered interactions, whereas Table 5 shows the relative values of $\Delta \mathrm{E}, \Delta \mathrm{E}_{\text {steric }}$ and $\Delta \mathrm{E}_{\text {orb }}$.

To depict the orbitalar contributions, natural bond orbital (NBO) analyses were also used. Results are better visualized in Figure 13.

NBO analyses showed to be in accordance with the other results. The strongest orbitalar interaction was noted for $\mathrm{O} 2-\mathrm{H} 2 \mathrm{~A} \cdots \mathrm{Cl}$, whereas the weakest was that related to $\mathrm{C} 4-\mathrm{H} 4 \cdots \mathrm{Cl}$.

From the single-crystal X-ray analysis, only H-bond interactions of MIK.Cl were detected. Bader's quantum theory of "atoms in molecules" (QTAIM) ${ }^{93}$ was therefore used to evaluate the so-called "bond critical point" (BCP), that is, the point with the minimal $\rho(\mathrm{r})$ value along the bond path, and the nature of the interaction (Figure 14). The type of interaction (H-bond, van der Waals, and so on) may be deduced by the charge density $\rho(r)$ values, which characterize each point in space. Additional parameters,
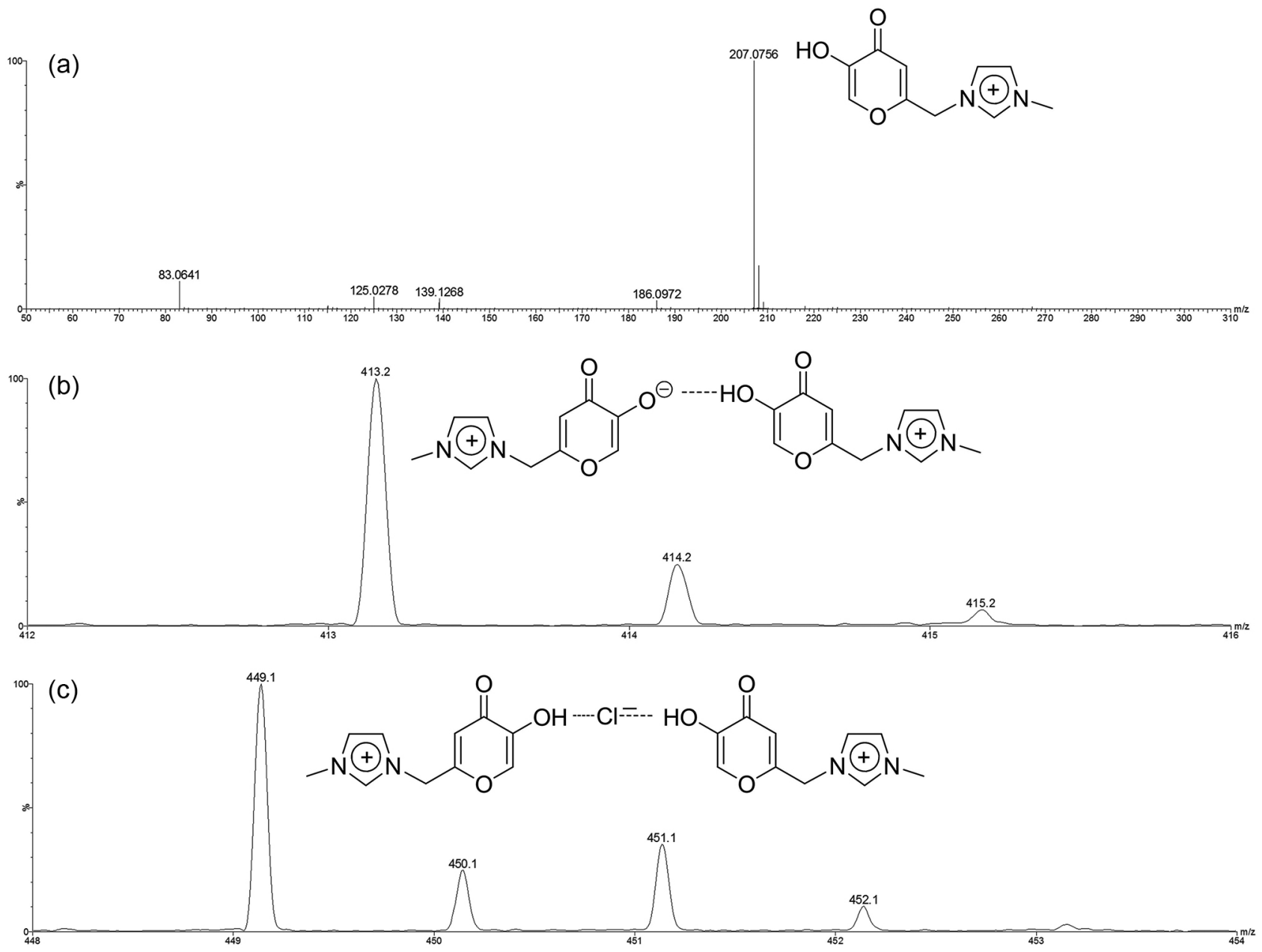

Figure 10. ESI(+)-MS of an aqueous solution of MIK.Cl (100 $\left.\mathrm{mmol} \mathrm{L}^{-1}\right)$. (a) The most abundant ion is attributed to the MIK cation of $m / z$. 207. Expansion of the ESI(+)-MS showing the supramolecular aggregate of (b) $m / z, 413$ attributed to the MIK cation with its zwitterionic partner and (c) of $m / z$, 449 of two MIK cations with one chlorine. 

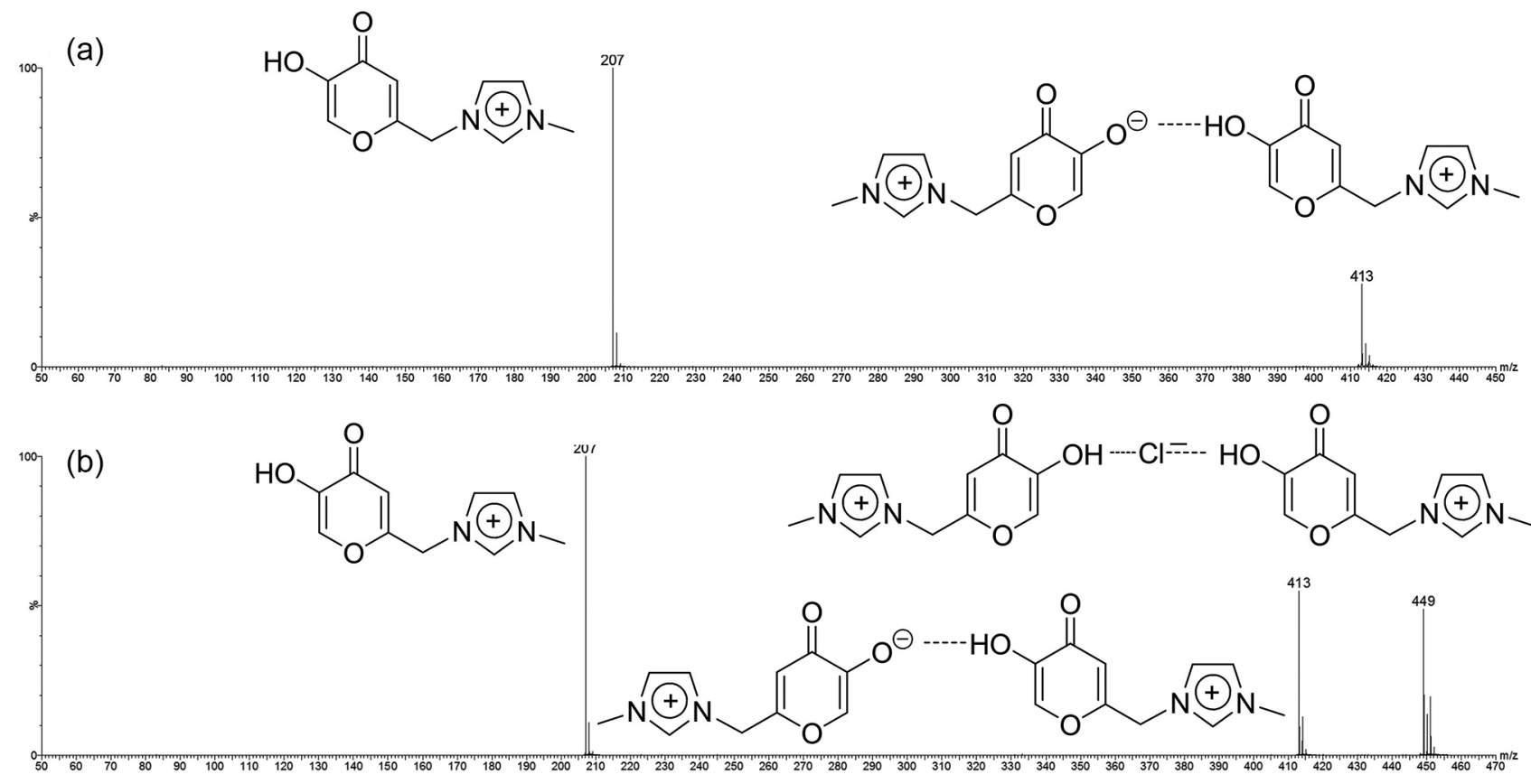

Figure 11. ESI(+)-MS/MS of the supramolecular aggregate of (a) $\mathrm{m} / \mathrm{z} 413$ and (b) $\mathrm{m} / \mathrm{z} 449$.

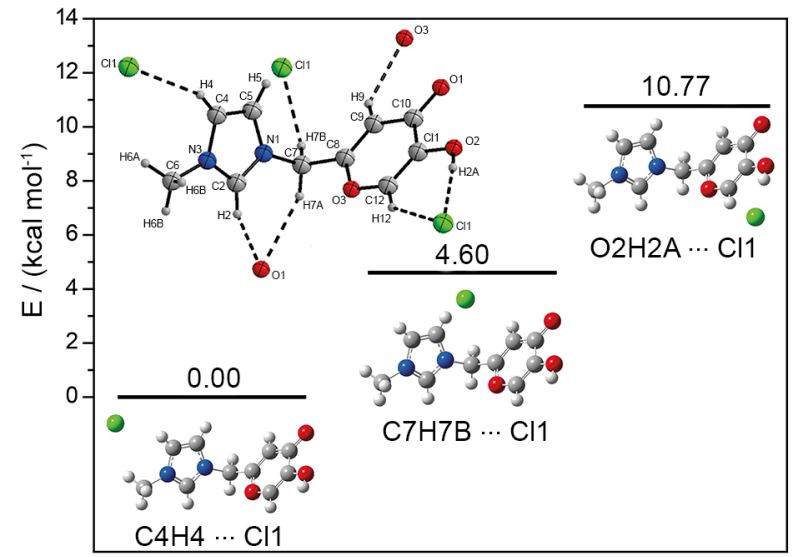

Figure 12. Relative energies (internal energy) of cation-anion interactions for the $\mathrm{Cl}^{-}$anion and the MIK cation at different positions based on the $\mathrm{X}$-ray structure (inset). A relative energy of $0.00 \mathrm{kcal} \mathrm{mol}^{-1}$ is associated with the most pronounced Coulombic interaction, whereas the relative energy of $10.77 \mathrm{kcal} \mathrm{mol}^{-1}$ has the most pronounced orbitalar contribution.

such as the gradient of $\rho(r)$, the Laplacian function of $\rho(r)$, and the matrix of the second derivatives of $\rho(r)$ (Hessian matrix) also characterize the system, as reviewed elsewhere. ${ }^{94-97}$ Popelier, ${ }^{98-100}$ Koch $^{101}$ and others, ${ }^{102}$ have already explored such parameters for depicting the nature of the different types of interactions. Calculations for MIK.Cl (Table 6) revealed that all interactions may be classified as $\mathrm{H}$-bonds considering $\rho$ between 0.002-0.035 (atomic units) and $\nabla^{2} \rho$ between 0.024-0.139 as the cutoff.

The results for QTAIM showed that interactions of MIK with the chloride anions occur via H-bonds, also in
Table 5. Relative energy decomposition (deconvolution) analysis using Morokuma's recommendations

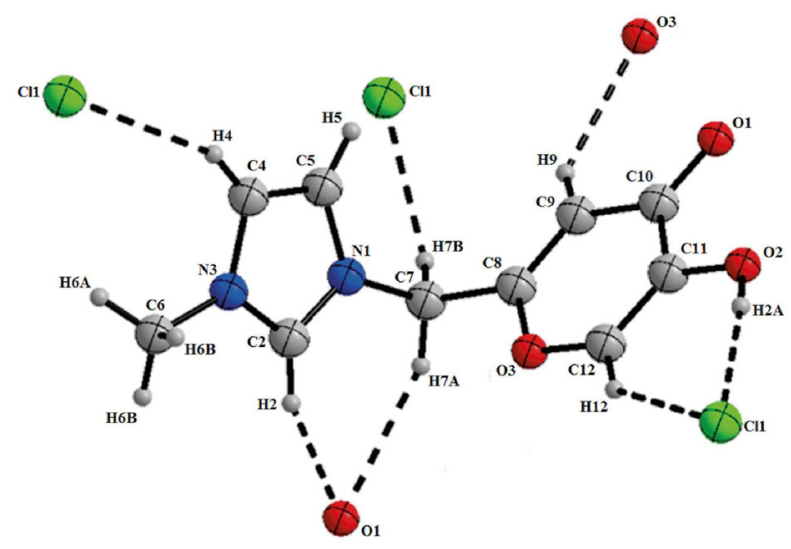

Relative energies $\quad \mathrm{C} 4-\mathrm{H} 4 \cdots \mathrm{Cl} 1 \quad \mathrm{C} 7-\mathrm{H} 7 \mathrm{~B} \cdots \mathrm{Cl} 1 \quad \mathrm{O} 2-\mathrm{H} 2 \mathrm{~A} \cdots \mathrm{Cl} 1$ / ( $\left.\mathrm{kcal} \mathrm{mol}^{-1}\right)$

\begin{tabular}{lccc}
\hline$\Delta$ E internal & 0.00 & 4.60 & 10.77 \\
$\Delta$ E orbitalar & 0.00 & -1.20 & -1.80 \\
$\Delta$ E steric & 0.00 & 5.80 & 12.57 \\
\hline
\end{tabular}

accordance with the X-ray analysis. On the whole, the calculations showed that the electrostatic interactions play major roles for ion-pairing in the structure of MIK. $\mathrm{Cl}$, but strong $\mathrm{H}$-bonds play crucial roles especially for the directionality of the structure. H-bonds are also responsible for the additional structural stabilization, in accordance, therefore, with recent conclusions for ILs/TSILs. ${ }^{2}$ 


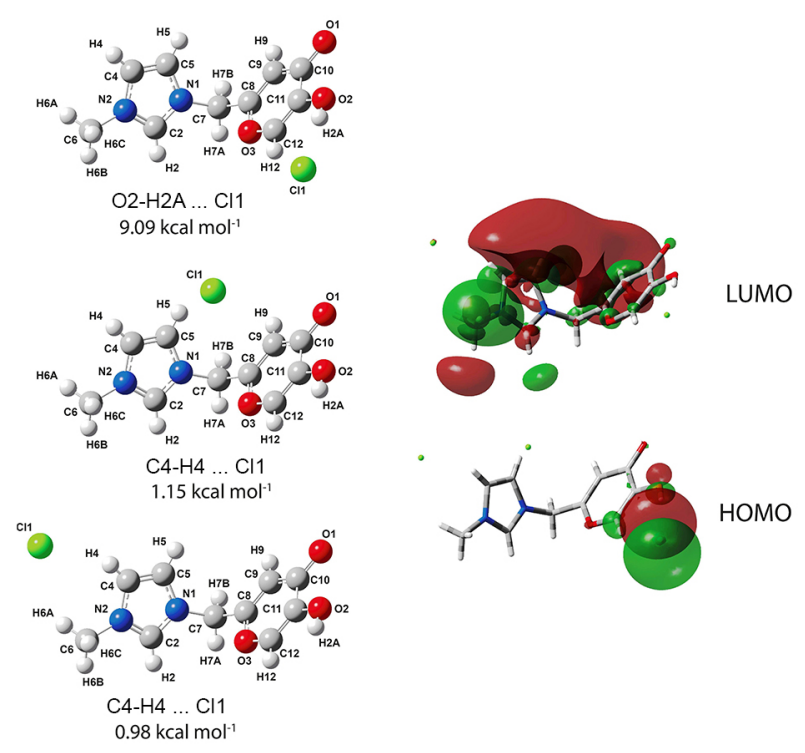

Figure 13. Interaction energies from natural bond orbital analyses (left) and orbital map (HOMO and LUMO) for the $\mathrm{O} 2-\mathrm{H} 2 \mathrm{~A} \cdots \mathrm{Cl} 1$ interaction (calculated for this ion pair).

\section{Conclusions}

The present data allowed a comprehensive evaluation of the supramolecular interactions and three-dimensional organization of the task-specific ionic liquid MIK.Cl. The use of a set of techniques formed by single-crystal X-ray diffration, NMR spectroscopy, UV-Vis spectrophotometry, conductivity measurements, SAXS, ESI-MS(/MS), and theoretical calculations has allowed proper understanding of the structural organization of MIK.Cl, revealing crucial contribution of H-bonds for the directionality and organization of its 3D structure. Preferential aggregation was also detected in water. The importance of H-bonds was pointed out by all techniques and proved to be in agreement with the aggregation behavior observed for MIK.Cl. The conclusions from this work form a baseline for future studies regarding the organizational properties and supramolecular interactions of TSILs.
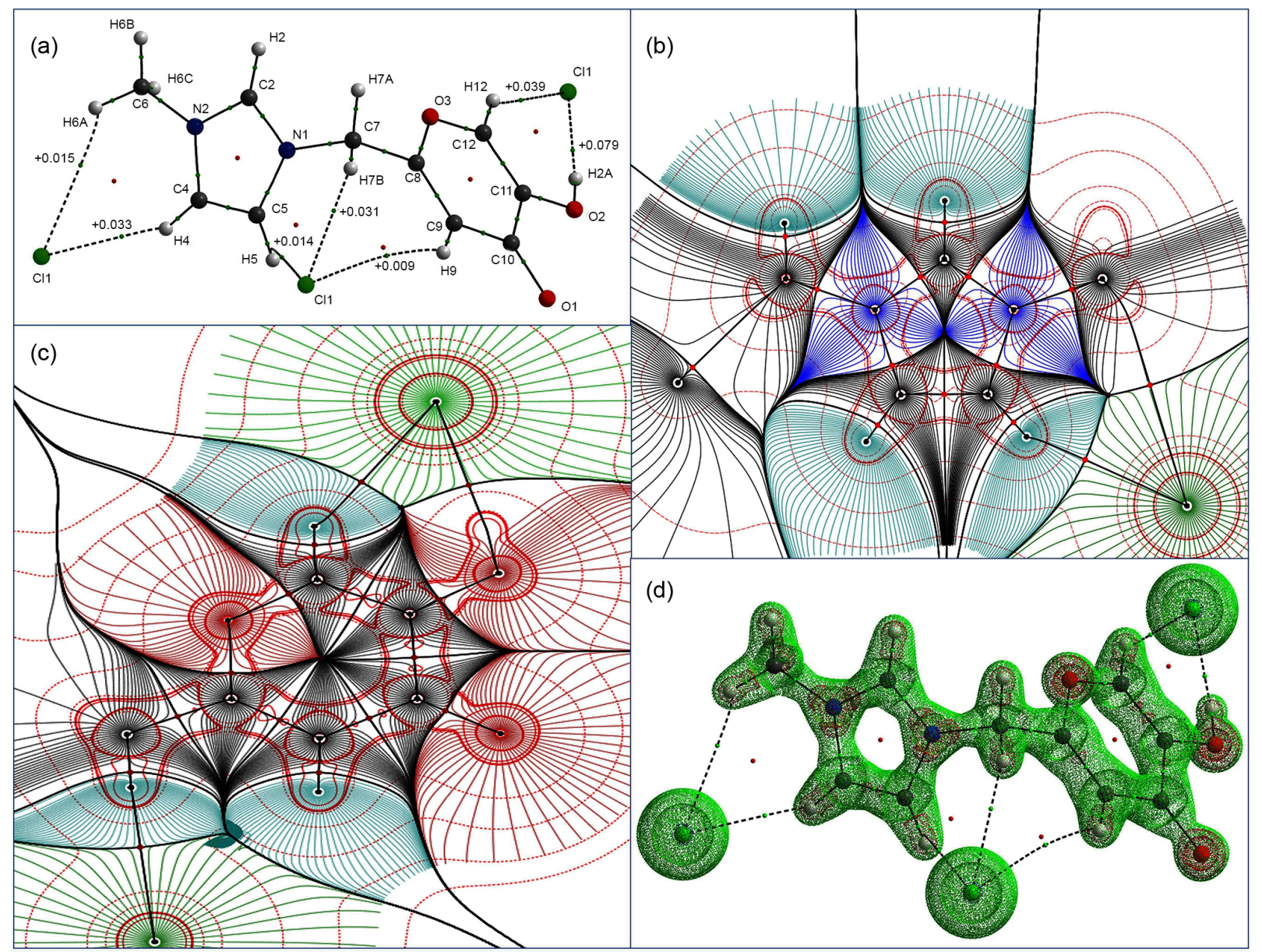

Figure 14. Results of quantum theory of "atoms in molecules" applied for MIK.Cl. (a) Critical points (show as green spots; see between the represented bond paths and interactions) and the calculated values for the Laplacian function of $\rho(r)$ in their bond critical point. (b, c) Gradient vector fields of charge densities associated with the representative topologies of the calculated electron density function for the atoms found in the imidazolium ring (b) and for the other part of the structure (c). Note that (b) and (c) also show the atom domains and their individual contributions in the molecule. (d) Three-dimensional view for the whole structure of MIK.Cl of the calculated Laplacian function of $\rho(r)$. 
Table 6. Calculated QTAIM (atomic units, a.u.) parameters of bond critical points (BCP), charge density ( $\rho$ ), Laplacian function $\left(\nabla^{2} \rho\right)$, ellipticity $(\varepsilon)$, kinetic energy $(\mathrm{K})$ and potential energy $(\mathrm{V})$ for MIK.Cl

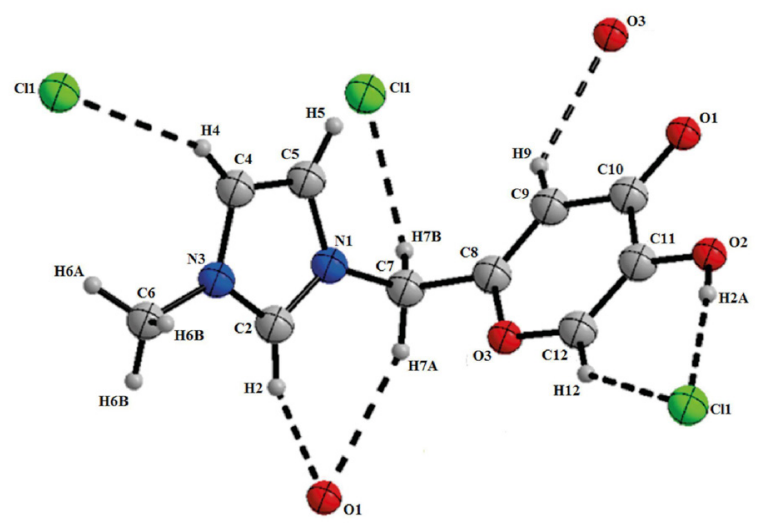

\begin{tabular}{|c|c|c|c|c|c|}
\hline $\mathrm{BCP}$ & $\rho /$ a.u. & $\nabla^{2} \rho /$ a.u. & $\varepsilon$ & $\mathrm{K} /$ a.u. & $\mathrm{V} / \mathrm{a} . \mathrm{u}$ \\
\hline $\mathrm{H} 12 \cdots \mathrm{Cl} 1$ (BCP1) & 0.011 & +0.039 & 0.082 & -0.002 & -0.006 \\
\hline $\mathrm{H} 2 \mathrm{~A} \cdots \mathrm{Cl} 1$ (BCP2) & 0.023 & +0.079 & 0.008 & -0.001 & -0.018 \\
\hline $\mathrm{H} 5 \cdots \mathrm{Cl} 1$ (BCP3) & 0.005 & +0.014 & 0.367 & -0.001 & -0.002 \\
\hline $\mathrm{H} 9 \cdots \mathrm{Cl} 1$ (BCP4) & 0.003 & +0.009 & 1.536 & ca. 0.000 & -0.001 \\
\hline H7B $\cdots \mathrm{Cl} 1$ (BCP5) & 0.010 & +0.031 & 0.042 & -0.001 & -0.006 \\
\hline $\mathrm{H} 4 \cdots \mathrm{Cl} 1$ (BCP6) & 0.010 & +0.033 & 0.020 & -0.002 & -0.005 \\
\hline H6A …Cl1 (BCP7) & 0.006 & +0.015 & 0.148 & -0.001 & -0.002 \\
\hline 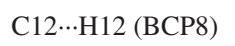 & 0.395 & -1.893 & 0.060 & +0.550 & -0.628 \\
\hline $\mathrm{O} 2 \cdots \mathrm{H} 2 \mathrm{~A}(\mathrm{BCP} 9)$ & 0.532 & -5.012 & 0.012 & +1.363 & -1.474 \\
\hline C5 $\cdots \mathrm{H} 5$ (BCP10) & 0.391 & -1.875 & 0.034 & +0.541 & -0.614 \\
\hline C9 $\cdots H 9$ (BCP11) & 0.386 & -1.797 & 0.010 & +0.540 & -0.631 \\
\hline C7 $\cdots$ H7B (BCP12) & 0.366 & -1.642 & 0.037 & +0.471 & -0.532 \\
\hline $\mathrm{H} 4 \cdots \mathrm{C} 4$ (BCP13) & 0.406 & -2.029 & 0.033 & +0.584 & -0.660 \\
\hline C6 $\cdots$ H6A (BCP14) & 0.369 & -1.638 & 0.052 & +0.483 & -0.556 \\
\hline
\end{tabular}

\section{Supplementary Information}

Supplementary information (Figures, a picture with Prof Roberto F. de Souza and experimental details) is available free of charge at http://jbcs.sbq.org.br as a PDF file.

\section{Acknowledgments}

This work was partially supported by CNPq, CAPES, FAPDF, INCT-Catalysis, Finatec, FAPESP, Petrobras and DPP-UnB. B. A. D. Neto and G. Machado also acknowledge LNLS (Brazilian Synchrotron Light Laboratory) for the use of the facilities.

(BADN) Prof Roberto F. de Souza (IQ-UFRGS) was a close friend. I had the privilege of a daily living with him during my PhD time period. Prof Roberto was an enthusiast! He was always teaching with passion and determination. Ionic liquids were among his passions; and this is why I chose to write about a TSIL as a contribution to the current special issue in catalysis. His contributions are outstanding not only for Brazilian science, but also worldwide. We included a picture of his last participation as examiner in a Master degree defense in the Supplementary Information, which was the first defense of a new Graduate Program (Programa de Pós-Graduação em Tecnologia Química e Biológica, PPGTQB) at the Chemistry Institute (Universidade de Brasília). Finally, I would like to add how flattered I am for contributing to the current special issue in catalysis and the possibility to honor the memory of Prof Roberto.

\section{References}

1. Fei, Z.; Dyson, P. J.; Chem. Commun. 2013, 49, 2594.

2. Dupont, J.; Acc. Chem. Res. 2011, 44, 1223.

3. Dupont, J.; Scholten, J. D.; Chem. Soc. Rev. 2010, 39, 1780. 
4. Plechkova, N. V.; Seddon, K. R.; Chem. Soc. Rev. 2008, 37, 123.

5. Hallett, J. P.; Welton, T.; Chem. Rev. 2011, 111, 3508.

6. Scholten, J. D.; Leal, B. C.; Dupont, J.; ACS Catal. 2012, 2, 184.

7. Dupont, J.; Meneghetti, M. R.; Curr. Opin. Colloid Interface Sci. 2013, 18, 54.

8. Dupont, J.; Eberlin, M. N.; Curr. Org. Chem. 2013, 17, 257.

9. Petkovic, M.; Seddon, K. R.; Rebelo, L. P. N.; Pereira, C. S.; Chem. Soc. Rev. 2011, 40, 1383.

10. Suarez, P. A. Z.; Ramalho, H. F.; Curr. Org. Chem. 2013, 17, 229.

11. Olivier-Bourbigou, H.; Magna, L.; Morvan, D.; Appl. Catal., A 2010, 373, 1.

12. Dong, K.; Zhang, S. J.; Chem. Eur. J. 2012, 18, 2748.

13. van Rantwijk, F.; Sheldon, R. A.; Chem. Rev. 2007, 107, 2757.

14. Parvulescu, V. I.; Hardacre, C.; Chem. Rev. 2007, 107, 2615.

15. Tang, S. K.; Baker, G. A.; Zhao, H.; Chem. Soc. Rev. 2012, 41, 4030.

16. Freire, M. G.; Claudio, A. F. M.; Araujo, J. M. M.; Coutinho, J. A. P.; Marrucho, I. M.; Lopes, J. N. C.; Rebelo, L. P. N.; Chem. Soc. Rev. 2012, 41, 4966.

17. Niedermeyer, H.; Hallett, J. P.; Villar-Garcia, I. J.; Hunt, P. A.; Welton, T.; Chem. Soc. Rev. 2012, 41, 7780.

18. Riduan, S. N.; Zhang, Y. G.; Chem. Soc. Rev. 2013, 42, 9055.

19. Bica, K.; Gaertner, P.; Eur. J. Org. Chem. 2008, 3235.

20. Prechtl, M. H. G.; Scholten, J. D.; Neto, B. A. D.; Dupont, J.; Curr. Org. Chem. 2009, 13, 1259.

21. Sharma, R.; Mahajan, R. K.; RSC Adv. 2014, 4, 748.

22. Weingartner, H.; Cabrele, C.; Herrmann, C.; Phys. Chem. Chem. Phys. 2012, 14, 415.

23. Ueno, K.; Tokuda, H.; Watanabe, M.; Phys. Chem. Chem. Phys. 2010, 12, 1649.

24. Fumino, K.; Reichert, E.; Wittler, K.; Hempelmann, R.; Ludwig, R.; Angew. Chem., Int. Ed. 2012, 51, 6236.

25. Tsuzuki, S.; Tokuda, H.; Mikami, M.; Phys. Chem. Chem. Phys. 2007, 9, 4780.

26. Peppel, T.; Roth, C.; Fumino, K.; Paschek, D.; Kockerling, M.; Ludwig, R.; Angew. Chem., Int. Ed. 2011, 50, 6661.

27. Lassegues, J. C.; Grondin, J.; Cavagnat, D.; Johansson, P.; J. Phys. Chem. A 2009, 113, 6419.

28. Danten, Y.; Cabaco, M. I.; Besnard, M.; J. Phys. Chem. A 2009, 113,2873

29. Zhao, W.; Leroy, F.; Heggen, B.; Zahn, S.; Kirchner, B.; Balasubramanian, S.; Muller-Plathe, F.; J. Am. Chem. Soc. 2009, 131, 15825.

30. Wang, X. Q.; Yu, L.; Jiao, J. J.; Zhang, H. N.; Wang, R.; Chen, H.; J. Mol. Liq. 2012, 173, 103.

31. Schrekker, H. S.; Silva, D. O.; Gelesky, M. A.; Stracke, M. P.; Schrekker, C. M. L.; Gonçalves, R. S.; Dupont, J.; J. Braz. Chem. Soc. 2008, 19, 426.
32. Cho, C. W.; Jungnickel, C.; Stolte, S.; Preiss, U.; Arning, J.; Ranke, J.; Krossing, I.; Thoming, J.; ChemPhysChem 2012, 13, 780.

33. Twu, P.; Zhao, Q. C.; Pitner, W. R.; Acree, W. E.; Baker, G. A.; Anderson, J. L.; J. Chromatogr. A 2011, 1218, 5311.

34. Luo, S. C.; Sun, S. W.; Deorukhkar, A. R.; Lu, J. T.; Bhattacharyya, A.; Lin, I. J. B.; J. Mater. Chem. 2011, 21, 1866.

35. Liu, X. M.; Song, Z. X.; Wang, H. J.; Struct. Chem. 2009, 20, 509.

36. Gutowski, K. E.; Maginn, E. J.; J. Am. Chem. Soc. 2008, 130, 14690.

37. Yu, G. R.; Zhang, S. J.; Zhou, G. H.; Liu, X. M.; Chen, X. C.; AIChE J. 2007, 53, 3210.

38. Paul, A.; Samanta, A.; J. Phys. Chem. B 2007, 111, 4724.

39. Zhang, Q. H.; Li, Z. P.; Zhang, J.; Zhang, S. G.; Zhu, L. Y.; Yang, J.; Zhang, X. P.; Deng, Y. Q.; J. Phys. Chem. B 2007, 111, 2864.

40. Saha, S.; Hamaguchi, H. O.; J. Phys. Chem. B 2006, 110, 2777.

41. Fei, Z. F.; Zhao, D. B.; Geldbach, T. J.; Scopelliti, R.; Dyson, P. J.; Eur. J. Inorg. Chem. 2005, 860.

42. Lee, K. M.; Chang, H. C.; Jiang, J. C.; Lu, L. C.; Hsiao, C. J.; Lee, Y. T.; Lin, S. H.; Lin, I. J. B.; J. Chem. Phys. 2004, 120, 8645.

43. Stancik, C. M.; Lavoie, A. R.; Schutz, J.; Achurra, P. A.; Lindner, P.; Gast, A. P.; Waymouth, R. M.; Langmuir 2004, 20, 596.

44. Allen, J. J.; Schneider, Y.; Kail, B. W.; Luebke, D. R.; Nulwala, H.; Damodaran, K.; J. Phys. Chem. B 2013, 117, 3877.

45. Katsyuba, S. A.; Vener, M. V.; Zvereva, E. E.; Fei, Z. F.; Scopelliti, R.; Laurenczy, G.; Yan, N.; Paunescu, E.; Dyson, P. J.; J. Phys. Chem. B 2013, 117, 9094.

46. Lee, S. G.; Chem. Commun. 2006, 1049.

47. Lombardo, M.; Trombini, C.; ChemCatChem 2010, 2, 135.

48. Sebesta, R.; Kmentova, I.; Toma, S.; Green Chem. 2008, 10, 484.

49. Zhang, H.; Cui, H.; Langmuir 2009, 25, 2604.

50. Lissner, E.; de Souza, W. F.; Ferrera, B.; Dupont, J.; ChemSusChem 2009, 2, 962.

51. Li, J. Z.; Peng, Y. Q.; Song, G. H.; Catal. Lett. 2005, 102, 159.

52. Dong, F.; Jun, L.; Xinli, Z.; Zhiwen, Y.; Zuliang, L.; J. Mol. Catal. A: Chem. 2007, 274, 208.

53. Safari, J.; Zarnegar, Z.; New J. Chem. 2014, 38, 358.

54. Sharma, N.; Sharma, U. K.; Kumar, R.; Richa; Sinha, A. K.; RSC Adv. 2012, 2, 10648.

55. Wang, L.; Li, H. J.; Li, P. H.; Tetrahedron 2009, 65, 364.

56. Siyutkin, D. E.; Kucherenko, A. S.; Struchkova, M. I.; Zlotin, S. G.; Tetrahedron Lett. 2008, 49, 1212.

57. Anjaiah, S.; Chandrasekhar, S.; Gree, R.; Tetrahedron Lett. 2004, 45, 569.

58. Geldbach, T. J.; Dyson, P. J.; J. Am. Chem. Soc. 2004, 126, 8114. 
59. Zhu, A. L.; Jiang, T.; Han, B. X.; Huang, J.; Zhang, J. C.; Ma, X. M.; New J. Chem. 2006, 30, 736.

60. Ramos, L. M.; Guido, B. C.; Nobrega, C. C.; Corrêa, J. R.; Silva, R. G.; de Oliveira, H. C. B.; Gomes, A. F.; Gozzo, F. C.; Neto, B. A. D.; Chem. Eur. J. 2013, 19, 4156.

61. Alvim, H. G. O.; de Lima, T. B.; de Oliveira, H. C. B.; Gozzo, F. C.; de Macedo, J. L.; Abdelnur, P. V.; Silva, W. A.; Neto, B. A. D.; ACS Catal. 2013, 3, 1420.

62. Alvim, H. G. O.; Bataglion, G. A.; Ramos, L. M.; de Oliveira, A. L.; de Oliveira, H. C. B.; Eberlin, M. N.; de Macedo, J. L.; da Silva, W. A.; Neto, B. A. D.; Tetrahedron 2014, 70, 3306.

63. Oliveira, F. F. D.; dos Santos, M. R.; Lalli, P. M.; Schmidt, E. M.; Bakuzis, P.; Lapis, A. A. M.; Monteiro, A. L.; Eberlin, M. N.; Neto, B. A. D.; J. Org. Chem. 2011, 76, 10140.

64. Medeiros, G. A.; da Silva, W. A.; Bataglion, G. A.; Ferreira, D. A. C.; de Oliveira, H. C. B.; Eberlin, M. N.; Neto, B. A. D.; Chem. Commun. 2014, 50, 338.

65. Rodrigues, T. S.; Silva, V. H. C.; Lalli, P. M.; de Oliveira, H. C. B.; da Silva, W. A.; Coelho, F.; Eberlin, M. N.; Neto, B. A. D.; J. Org. Chem. 2014, 79, 5239.

66. Alvim, H. G. O.; Lima, T. B.; de Oliveira, A. L.; de Oliveira, H. C. B.; Silva, F. M.; Gozzo, F. C.; Souza, R. Y.; da Silva, W. A.; Neto, B. A. D.; J. Org. Chem. 2014, 79, 3383.

67. Diniz, J. R.; Correa, J. R.; Moreira, D. D.; Fontenele, R. S.; de Oliveira, A. L.; Abdelnur, P. V.; Dutra, J. D. L.; Freire, R. O.; Rodrigues, M. O.; Neto, B. A. D.; Inorg. Chem. 2013, 52, 10199.

68. dos Santos, M. R.; Diniz, J. R.; Arouca, A. M.; Gomes, A. F.; Gozzo, F. C.; Tamborim, S. M.; Parize, A. L.; Suarez, P. A. Z.; Neto, B. A. D.; ChemSusChem 2012, 5, 716.

69. dos Santos, M. R.; Gomes, A. F.; Gozzo, F. C.; Suarez, P. A. Z.; Neto, B. A. D.; ChemSusChem 2012, 5, 2383.

70. dos Santos, M. R.; Coriolano, R.; Godoi, M. N.; Monteiro, A. L.; de Oliveira, H. C. B.; Eberlin, M. N.; Neto, B. A. D.; New J. Chem. 2014, 38, 2958.

71. Mota, A. A. R.; Gatto, C. C.; Machado, G.; de Oliveira, H. C. B.; Fasciotti, M.; Bianchi, O.; Eberlin, M. N.; Neto, B. A. D.; J. Phys. Chem. C 2014, 118, 17878.

72. Dupont, J.; Suarez, P. A. Z.; De Souza, R. F.; Burrow, R. A.; Kintzinger, J. P.; Chem. Eur. J. 2000, 6, 2377.

73. Consorti, C. S.; Suarez, P. A. Z.; de Souza, R. F.; Burrow, R. A.; Farrar, D. H.; Lough, A. J.; Loh, W.; da Silva, L. H. M.; Dupont, J.; J. Phys. Chem. B 2005, 109, 4341.

74. Steiner, T.; Angew. Chem., Int. Ed. 2002, 41, 48.

75. Corvo, M. C.; Sardinha, J.; Menezes, S. C.; Einloft, S.; Seferin, M.; Dupont, J.; Casimiro, T.; Cabrita, E. J.; Angew. Chem., Int. Ed. 2013, 52, 13024.

76. Otrelo-Cardoso, A. R.; Schwuchow, V.; Rodrigues, D.; Cabrita, E. J.; Leimkuehler, S.; Romao, M. J.; Santos-Silva, T.; PLoS One 2014, 9, e87295.

77. Figueiredo, A. M.; Sardinha, J.; Moore, G. R.; Cabrita, E. J.; Phys. Chem. Chem. Phys. 2013, 15, 19632.
78. Casimiro, M. H.; Corvo, M. C.; Ramos, A. M.; Cabrita, E. J.; Ramos, A. M.; Ferreira, L. M.; Mater. Chem. Phys. 2013, 138, 11.

79. Vold, R. L.; Waught, J. S.; Klein, M. P.; Phelps, D. E.; Chem. Phys. 1968, 48, 3831.

80. Desando, M. A.; Lahajnar, G.; Sepe, A.; J. Colloid Interface Sci. 2010, 345, 338.

81. Spickermann, C.; Thar, J.; Lehmann, S. B. C.; Zahn, S.; Hunger, J.; Buchner, R.; Hunt, P. A.; Welton, T.; Kirchner, B.; J. Chem. Phys. 2008, 129, 104505.

82. Vila, J.; Gines, P.; Rilo, E.; Cabeza, O.; Varela, L. M.; Fluid Phase Equilib. 2006, 247, 32.

83. Bowers, J.; Butts, C. P.; Martin, P. J.; Vergara-Gutierrez, M. C.; Heenan, R. K.; Langmuir 2004, 20, 2191.

84. Zhang, H. C.; Liang, H. J.; Wang, J. J.; Li, K.; Z. Phys. Chem. 2007, 221, 1061.

85. Neumann, B.; J. Phys. Chem. B 2001, 105, 8268.

86. Wang, Y. D.; Cakmak, M.; Polymer 2001, 42, 4233.

87. Korgel, B. A.; Fitzmaurice, D.; Phys. Rev. B: Condens. Matter Mater. Phys. 1999, 59, 14191.

88. Verma, R.; Marand, H.; Hsiao, B.; Macromolecules 1996, 29 , 7767.

89. Schatzbe, P.; J. Phys. Chem. 1967, 71, 4569.

90. Perera, A.; Sokolic, F.; Zoranic, L.; Phys. Rev. E: Stat., Nonlinear, Soft Matter Phys. 2007, 75, 060502.

91. Barhdadi, R.; Troupel, M.; Comminges, C.; Laurent, M.; Doherty, A.; J. Phys. Chem. B 2011, 116, 277.

92. Coelho, F.; Eberlin, M. N.; Angew. Chem., Int. Ed. 2011, 50, 5261.

93. Bader, R. F. W.; Chem. Rev. 1991, 91, 893.

94. Bader, R. F. W.; Popelier, P. L. A.; Keith, T. A.; Angew. Chem., Int. Ed. 1994, 33, 620.

95. Bone, R. G. A.; Bader, R. F. W.; J. Phys. Chem. 1996, 100, 10892.

96. Hernandez-Trujillo, J.; Bader, R. F. W.; J. Phys. Chem. A 2000, 104, 1779.

97. Bader, R. F. W.; J. Phys. Chem. A 1998, 102, 7314.

98. Popelier, P. L. A.; J. Phys. Chem. A 1999, 103, 2883.

99. O’Brien, S. E.; Popelier, P. L. A.; Can. J. Chem. 1999, 77, 28.

100. Popelier, P. L. A.; J. Phys. Chem. A 1998, 102, 1873.

101. Koch, U.; Popelier, P. L. A.; J. Phys. Chem. 1995, 99, 9747.

102. Bushmarinov, I. S.; Lyssenko, K. A.; Antipin, M. Y.; Russ. Chem. Rev. 2009, 78, 283.

Submitted: August 15, 2014

Published online: September 23, 2014

FAPESP has sponsored the publication of this article. 